Article

\title{
Synthesis and Regeneration of Nickel-Based Catalysts for Hydrodeoxygenation of Beech Wood Fast Pyrolysis Bio-Oil
}

\author{
Caroline Carriel Schmitt ${ }^{1,2, *}$, María Belén Gagliardi Reolon ${ }^{1,3}$, Michael Zimmermann ${ }^{1}$, \\ Klaus Raffelt ${ }^{1}$, Jan-Dierk Grunwaldt ${ }^{1,4} \oplus$ and Nicolaus Dahmen ${ }^{1}$ \\ 1 Institute of Catalysis Research and Technology (IKFT), Karlsruhe Institute of Technology (KIT), \\ 76344 Eggenstein-Leopoldshafen, Germany; magagliardi@itba.edu.ar (M.B.G.R.); \\ michael.zimmermann@kit.edu (M.Z.); klaus.raffelt@kit.edu (K.R.); grunwaldt@kit.edu (J.-D.G.); \\ nicolaus.dahmen@kit.edu (N.D.) \\ 2 Institute of Microstructure Technology (IMT), Karlsruhe Institute of Technology (KIT), \\ 76344 Eggenstein-Leopoldshafen, Germany \\ 3 Instituto Tecnologico de Buenos Aires (ITBA), Buenos Aires C1106ACD, Argentina \\ 4 Institute for Chemical Technology and Polymer Chemistry (ITCP), Karlsruhe Institute of Technology (KIT), \\ 76131 Karlsruhe, Germany \\ * Correspondence: caroline.schmitt@partner.kit.edu
}

Received: 17 August 2018; Accepted: 8 October 2018; Published: 12 October 2018

check for updates

\begin{abstract}
Four nickel-based catalysts are synthesized by wet impregnation and evaluated for the hydrotreatment/hydrodeoxygenation of beech wood fast-pyrolysis bio-oil. Parameters such as elemental analysis, $\mathrm{pH}$ value, and water content, as well as the heating value of the upgraded bio-oils are considered for the evaluation of the catalysts' activity and catalyst reuse in cycles of hydrodeoxygenation after regeneration. The reduction temperature, selectivity and hydrogen consumption are distinct among them, although all catalysts tested produce upgraded bio-oils with reduced oxygen concentration, lower water content and higher energy density. $\mathrm{Ni} / \mathrm{SiO}_{2}$, in particular, can remove more than $50 \%$ of the oxygen content and reduce the water content by more than $80 \%$, with low coke and gas formation. The evaluation over four consecutive hydrotreatment reactions and catalyst regeneration shows a slightly reduced hydrodeoxygenation activity of $\mathrm{Ni} / \mathrm{SiO}_{2}$, mainly due to deactivation caused by sintering and adsorption of poisoning substances, such as sulfur. Following the fourth catalyst reuse, the upgraded bio-oil shows $43 \%$ less oxygen in comparison to the feedstock and properties comparable to the upgraded bio-oil obtained with the fresh catalyst. Hence, nickel-based catalysts are promising for improving hardwood fast-pyrolysis bio-oil properties, especially monometallic nickel catalysts supported on silica.
\end{abstract}

Keywords: hydrodeoxygenation; fast-pyrolysis bio-oil; nickel catalyst; upgrading

\section{Introduction}

The increase in global energy demand, depletion of fossil fuel reserves and climate change issues have drawn attention to renewable alternatives, particularly to biomass [1-3], considering its $\mathrm{CO}_{2}$ neutrality for fuel applications and widespread availability [1,4]. Products such as heat, power, biomaterials, chemical compounds, and transportation fuels can be obtained from biomass [5]. Considering this purpose, thermochemical, chemical-catalytical or biological processes are used. Regarding the first category, combustion, gasification and pyrolysis are most common. Although considered the simplest way to convert biomass in either power or heat, combustion shows high emissions and ash generation [5]. Gasification is considered a very efficient method to obtain 
fuels, but it requires a high investment due to large-scale installations, storage and transportation [6]. Therewith, pyrolysis has been considered a promising process as it balances simple operation techniques with reasonable costs.

Pyrolysis is a thermochemical process in which the biomass is heated and converted in an inert atmosphere into a liquid fraction called bio-oil, a carbon-rich solid (biochar) and a mixture of non-condensable gases [7]. The bio-oil obtained has poorer physical and chemical characteristics if compared to liquid fossil fuels. The heating value is usually lower, only $40-50 \%$ compared to conventional fossil fuels $(42-45 \mathrm{MJ} / \mathrm{Kg}$ ), mainly due to the high oxygen and water content. Additionally, it shows high viscosity, low chemical stability and solid particles [8-10] due to incomplete solid separation or polymerization reactions during storage, for example. Carboxylic acids present in the bio-oil composition lead to high acidity ( $\mathrm{pH}$ value around 2-3.7), resulting in a bio-oil with potentially corrosive properties. Furthermore, it is highly unstable during storage due to ongoing chemical reactions, resulting in larger molecules by polymerization, etherification and esterification [9], for example. Additionally, it is immiscible with fossil fuels and tends to undergo phase separation when stored for a long time. Considering these poor fuel properties, the direct application of bio-oil is limited to furnaces and boilers, being unsuitable for application in gas turbines, diesel engines and other applications without further treatment [11]. Concerning bio-oil production today, wood with low ash content is used, leading to relatively "well-natured" bio-oils. Using ash-rich feedstocks, bio-oil yield and quality is decreased, while the tendency for phase separation increases.

To improve these properties and obtain a product resembling diesel fuel, bio-oil requires an additional upgrading treatment. Upgraded bio-oil can then be used as feedstock for producing chemicals, such as phenols for resin production, additives for fertilizers and pharmaceutical industries, as well as flavoring agents in the food industry [12]. Regarding terms of energetic use, upgraded bio-oil might be used as feedstock in oil refineries and fuels in engines [13].

A variety of upgrading techniques already have been proposed, such as catalytic cracking, hydrodeoxygenation (HDO) and esterification in supercritical fluids [14]. Among them, HDO appears to be a propitious route, due to its flexibility with respect to the biomass feed, the good economy of the input materials, and its compatibility with refinery infrastructures [15]. HDO is a high-pressure catalytic treatment in which oxygen is removed by hydrogen resulting in water, which is environmentally benign [16]. Usually, sulfides, noble metals and transition metal catalysts are used [17]. Noble metals such as Pt, Pd and Ru have been evaluated widely for HDO and are often the first choice in hydrogenation reactions. Additionally, they have a low tendency to be poisoned by the sulfur present in the bio-oil [18]. Their relatively high costs, however, prevent them from being widely used. Recently, nickel-based catalysts have become more attractive, considering their lower price, availability, activity and reduced hydrogen consumption [10,19]. Jin et al. [20] evaluated a series of nickel-based catalysts on different supports $\left(\mathrm{SiO}_{2}, \mathrm{Al}_{2} \mathrm{O}_{3}, \mathrm{AC}\right.$ and SBA-15 mesoporous silica) for the $\mathrm{HDO}$ of anisole, used as a model compound. Boscagli et al. [21] investigated the HDO of the bio-oil light phase over a variety of nickel-based catalysts $\left(\mathrm{NiCu} / \mathrm{Al}_{2} \mathrm{O}_{3}, \mathrm{Ni} / \mathrm{SiO}_{2}, \mathrm{Ni} / \mathrm{ZrO}_{2}, \mathrm{Ni} / \mathrm{TiO}_{2}\right.$ and $\mathrm{NiW} / \mathrm{AC}$ ). Dongil et al. [22] studied the HDO of guaiacol over nickel-based catalysts, using different carbon-based supports.

The combination of nickel in bimetallic catalysts has also attracted attention for HDO, especially in combination with copper. Ardiyanti et al. [23] evaluated the application of $\mathrm{NiCu}$ at different loadings supported in $\delta-\mathrm{Al}_{2} \mathrm{O}_{3}$ for upgrading of model compounds and fast-pyrolysis bio-oil. Dongil et al. [24] investigated the effect of $\mathrm{Cu}$ loading on nickel catalysts supported in carbon nanotubes over the HDO of guaiacol. Mortensen et al. [25] screened different catalysts, including $\mathrm{NiCu} / \mathrm{SiO}_{2}$ for phenol $\mathrm{HDO}$ and, more recently, Boscagli et al. [26] tested $\mathrm{NiCu} / \mathrm{Al}_{2} \mathrm{O}_{3}$ for the $\mathrm{HDO}$ of phenol and bio-oils reusing the catalyst after a regeneration step.

The investigation of nickel and nickel-copper catalysts on $\mathrm{SiO}_{2}$ and $\mathrm{ZrO}_{2}$ supports with real feedstock (fast-pyrolysis bio-oil) is of interest, especially with respect to the lower acidity in comparison to $\mathrm{Al}_{2} \mathrm{O}_{3}$, a commonly studied support for HDO catalysts [27]. Many studies are focused on 
alumina-supported catalysts $\left(\mathrm{Al}_{2} \mathrm{O}_{3}\right)[23,26]$ and upgrading applying model compounds $[20,22]$ but supports with higher stability are required. The alumina-support is well known for its acidity, tendency for increased coke formation, low water tolerance, and conversion to boehmite, resulting in the oxidation and deactivation of the active metal $[15,28,29]$. According to He et al. [28], the selection of the support for HDO of bio-oils, must consider the resistance to the water content, the acidity of the supports to reduce coke formation, the porosity and its ability to keep the active metal dispersed for the activation of hydrogen. Hence, the investigation of different supports, such as $\mathrm{SiO}_{2}$ and $\mathrm{ZrO}_{2}$, appears interesting, especially when including catalyst regeneration in consecutive cycles of HDO-regeneration, evaluating the thermal stability of the catalyst [30]. Presently, only a few works have investigated the regeneration and evaluation of the reuse of the catalyst [26]. Most works, in fact, only consider one regeneration step and do not contemplate $\mathrm{Ni}$ catalysts [26,31,32]. It is an essential step to reduce costs, minimizing the waste generation at the same time helping to increase the reusability and recyclability of the catalysts, extending its lifetime [33]. Additionally, previous studies considered the HDO of model compounds whereas others considered the application of fast pyrolysis bio-oil. Usually, different temperature, pressure and reactor designs are used, which makes the comparison of the performance of different nickel-based catalysts difficult.

The current work synthesizes, characterizes and evaluate four nickel-based catalysts for a multi-phase fast-pyrolysis bio-oil upgrading. Supports with higher stability $\left(\mathrm{SiO}_{2}\right.$ and $\left.\mathrm{ZrO}_{2}\right)$ are selected. The catalyst with the best performance is then reused in subsequent HDO-regeneration steps, resulting in four consecutive reactions. Finally, the performance and the catalytic activity along the HDO-regeneration steps are assessed and discussed.

\section{Results}

\subsection{Characterization of the Synthesized Catalysts}

The results obtained from the temperature programmed reduction $\left(\mathrm{H}_{2}-\mathrm{TPR}\right)$, in Figure 1, were useful to identify the catalysts' reduction temperatures before the hydrodeoxygenation (HDO) reactions. The $\mathrm{H}_{2}$-TPR profile for $\mathrm{Ni} / \mathrm{SiO}_{2}$ showed a clear peak at $350{ }^{\circ} \mathrm{C}$, while the peak for $\mathrm{Ni} / \mathrm{ZrO}_{2}$ is found between $350-400{ }^{\circ} \mathrm{C}$, in agreement with literature $[21,34,35]$. Since the reduction of bulk Ni oxide occurs around $400-450{ }^{\circ} \mathrm{C}[36,37]$, the reduction temperature of $\mathrm{Ni} / \mathrm{SiO}_{2}$ and $\mathrm{Ni} / \mathrm{ZrO}{ }_{2}$ was set to $500{ }^{\circ} \mathrm{C}$ to ensure a full reduction before hydrodeoxygenation (HDO) reactions. The addition of $\mathrm{Cu}$ to $\mathrm{Ni}[36,37]$, as well as the higher loading of $\mathrm{Ni}[38,39]$ seems to promote the reduction of $\mathrm{Ni}$ oxide, as for both bimetallic $\mathrm{NiCu}$ catalysts the temperature of reduction is lower compared to monometallic $\mathrm{Ni}$ catalysts. Concerning $\mathrm{NiCu} / \mathrm{SiO}_{2}$, it occurs at $300{ }^{\circ} \mathrm{C}$, while for $\mathrm{NiCu} / \mathrm{ZrO}_{2}$ it was closer to $200{ }^{\circ} \mathrm{C}$. Different peaks are present in the $\mathrm{H}_{2}$-TPR profiles, attributed to bulk nickel oxide reduction, reduction of $\mathrm{Cu}(\mathrm{II})$ to $\mathrm{Cu}(0)$ (below $250^{\circ} \mathrm{C}$ ), as well as reduction of bimetallic $\mathrm{NiCu}$ species which, according to Ardiyanti et al. [40], should occur approximately in the range of $290-390{ }^{\circ} \mathrm{C}$. Regarding the current catalysts, most of the reduction was observed at lower temperatures. Consequently, the reduction of $\mathrm{NiCu}$ catalyst was set at $350^{\circ} \mathrm{C}$.

Powder X-ray diffraction (XRD), provided information about the crystalline structure of the catalyst (Figure 2). Both $\mathrm{SiO}_{2}$-supported catalysts show similar XRD patterns. The reflections located at $37.25^{\circ}$ and $43.29^{\circ}$ indicate the presence of $\mathrm{Ni}$ oxide $(\mathrm{NiO})$ in the calcined catalysts. Additionally, metallic Ni was identified due to the reflections at $44.49^{\circ}, 51.85^{\circ}, 76.38^{\circ}, 92.93^{\circ}$ and $98.44^{\circ}$. Following the reduction, reflections attributed to $\mathrm{NiO}$ disappeared, remaining just metallic $\mathrm{Ni}$ reflections. A similar behavior can be seen for $\mathrm{Ni} / \mathrm{ZrO}_{2}$ and $\mathrm{NiCu} / \mathrm{ZrO}_{2}$ (Figure 2). Both $\mathrm{NiO}$ and metallic $\mathrm{Ni}$ are present in the calcined catalyst. Subsequently, the reduction reflections of $\mathrm{NiO}$ are no longer observed for $\mathrm{Ni} / \mathrm{ZrO}_{2}$ and showed a reduced intensity for $\mathrm{NiCu} / \mathrm{ZrO}_{2}$. Reflections attributed to copper were not observed in the bimetallic catalysts, which can be a result of high dispersion of the metal, as well as low concentration [21,23]. 

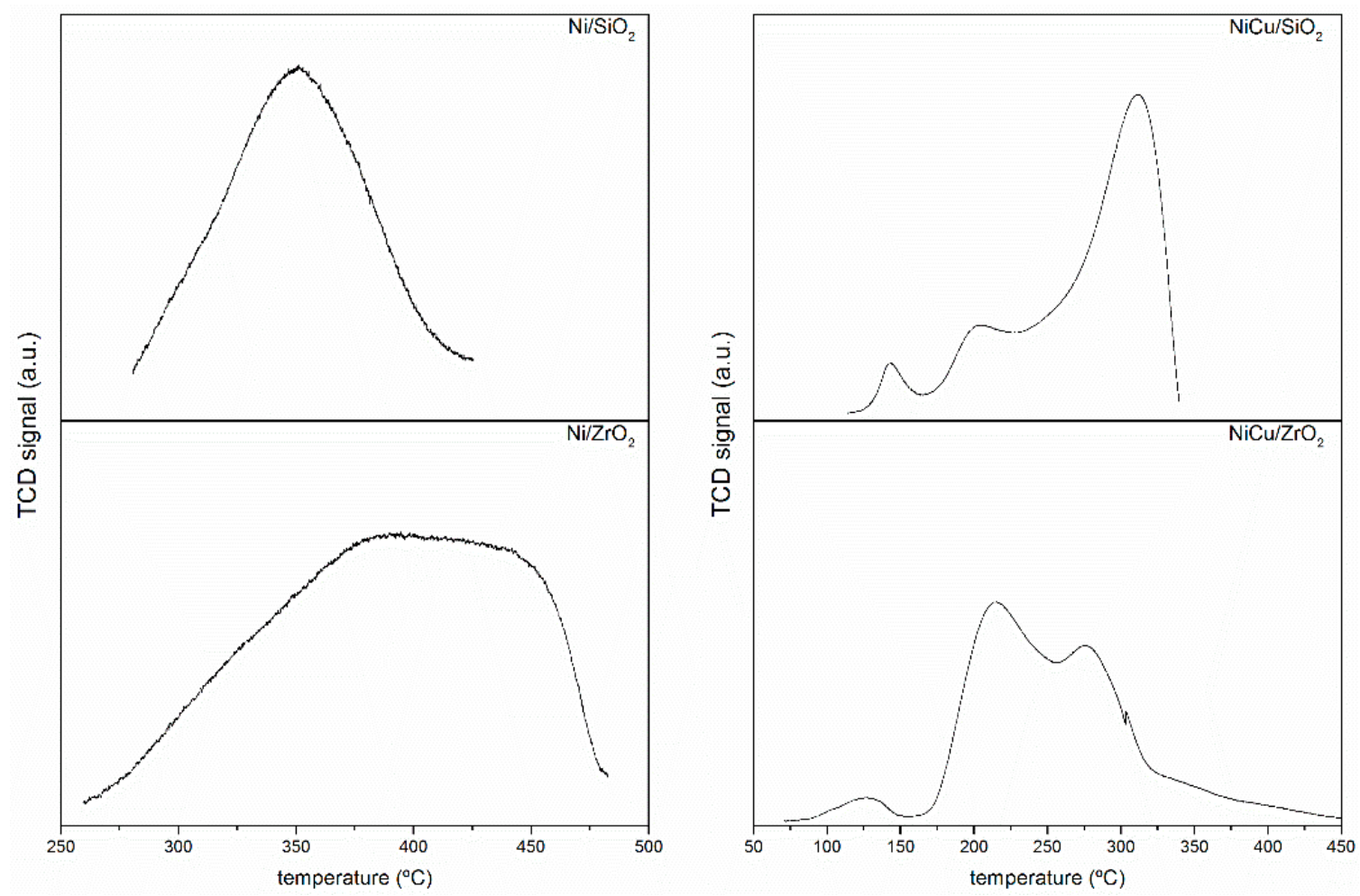

Figure 1. Temperature programmed reduction profile for the nickel-based catalysts. TCD: Thermal conductivity detector; a.u.: arbitrary units.
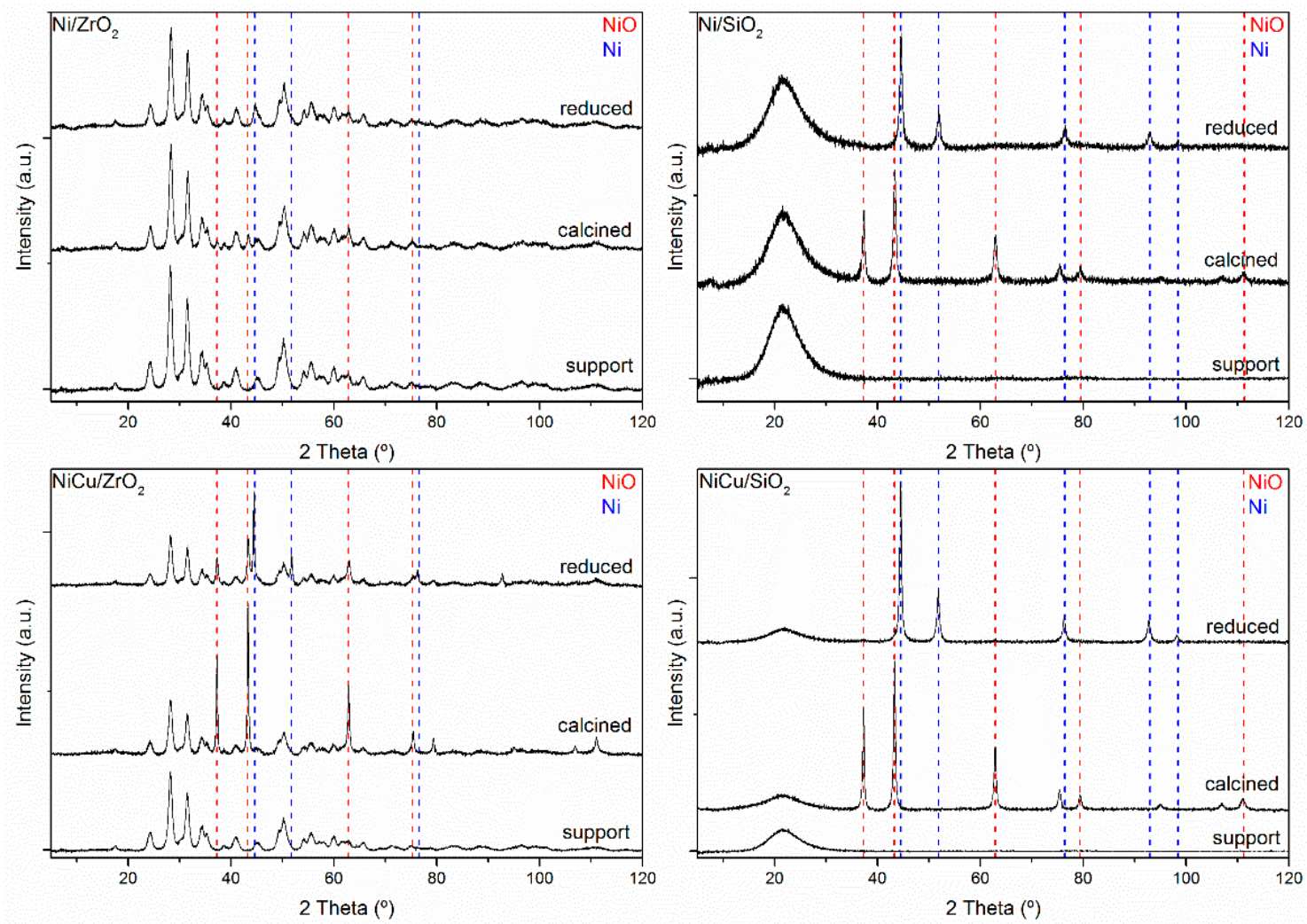

Figure 2. X-ray powder diffraction of the freshly synthesized catalysts, $\mathrm{Ni} / \mathrm{ZrO}_{2}, \mathrm{Ni} / \mathrm{SiO}_{2}, \mathrm{NiCu} / \mathrm{ZrO}_{2}$ and $\mathrm{NiCu} / \mathrm{SiO}_{2}$. a.u.: arbitrary units. 
The crystallite sizes were estimated using the Scherrer equation. The crystallite size was $17.7 \mathrm{~nm}$ for $\mathrm{Ni} / \mathrm{SiO}_{2}$, whereas for $\mathrm{NiCu} / \mathrm{SiO}_{2}$, the value was estimated to be $21.4 \mathrm{~nm}$. NiCu$/ Z \mathrm{ZrO}_{2}$ showed a crystallite size of $43.3 \mathrm{~nm}$ and the crystallite size of $\mathrm{Ni} / \mathrm{ZrO}_{2}$ was estimated at $9.7 \mathrm{~nm}$.

The metal concentration, as well as the specific surface area, is compiled in Table 1 . The $\mathrm{Ni} / \mathrm{SiO}_{2}$ catalyst displays the highest specific surface area $\left(215 \mathrm{~m}^{2} / \mathrm{g}\right)$, while $\mathrm{NiCu} / \mathrm{ZrO}_{2}$ shows the lowest $\left(50 \mathrm{~m}^{2} / \mathrm{g}\right)$. Usually, $\mathrm{SiO}_{2}$-supported catalysts show higher surface areas in comparison to $\mathrm{ZrO}_{2}$-supported catalysts [41]. The BET surface area of the catalysts, as well as the micropore area and volume, is reduced with the addition of $\mathrm{Cu}$ and higher nickel loading. This behavior was also observed by Dongil et al. [24] and Zhang et al. [42]. Furthermore, no micropores were observed in the zirconia-supported catalysts.

Table 1. BET surface area, pore area, volume, diameter, and metal content in the freshly synthesized catalysts.

\begin{tabular}{|c|c|c|c|c|}
\hline Properties & $\mathrm{Ni} / \mathrm{SiO}_{2}$ & $\mathrm{Ni} / \mathrm{ZrO}_{2}$ & $\mathrm{NiCu} / \mathrm{SiO}_{2}$ & $\mathrm{NiCu} / \mathrm{ZrO}_{2}$ \\
\hline BET surface area $\left(\mathrm{m}^{2} / \mathrm{g}\right)$ & 215 & 65 & 156 & 50 \\
\hline Micropore area $\left(\mathrm{m}^{2} / \mathrm{g}\right)$ & 24 & 0 & 12 & 0 \\
\hline Micropore volume $\left(\mathrm{cm}^{3} / \mathrm{g}\right)$ & 0.009 & 0 & 0.004 & 0 \\
\hline Pore diameter (nm) & 17.1 & 12.7 & 17.1 & 10.2 \\
\hline Ni (wt.\%) & 7.9 & 8.0 & 27.9 & 27.3 \\
\hline $\mathrm{Cu}(w t . \%)$ & - & - & 3.2 & 3.1 \\
\hline
\end{tabular}

\subsection{Hydrotreatment Reactions}

\subsubsection{Upgraded Bio-Oil Yields and Properties}

The HDO reactions with $\mathrm{Ni} / \mathrm{SiO}_{2}$ showed the highest yield of upgraded bio-oil (49.36 wt.\%), and the lowest yields of the aqueous phase (35.57 wt.\%) and solids (Table 2). These tendencies were not clear for the remaining catalysts. The lowest yield of upgraded bio-oil (45.32 wt.\%) was obtained with $\mathrm{Ni} / \mathrm{ZrO}_{2}$, while $\mathrm{NiCu} / \mathrm{ZrO}_{2}$ showed the highest production of solids $(0.32 \mathrm{wt} . \%)$ and aqueous phase (43.52 wt.\%). The highest production of gas was obtained with $\mathrm{Ni} / \mathrm{ZrO}_{2}(4.54 \mathrm{wt} . \%)$ whereas the lowest was obtained with $\mathrm{NiCu} / \mathrm{SiO}_{2}$ (3.56 wt.\%).

Table 2. Mass balance, elemental analysis and physicochemical properties of the upgraded bio-oils obtained with fresh Ni-based catalysts.

\begin{tabular}{|c|c|c|c|c|}
\hline Properties & $\mathrm{Ni} / \mathrm{SiO}_{2}$ & $\mathrm{Ni} / \mathrm{ZrO}_{2}$ & $\mathrm{NiCu} / \mathrm{SiO}_{2}$ & $\mathrm{NiCu} / \mathrm{ZrO}_{2}$ \\
\hline \multicolumn{5}{|l|}{ Mass balance } \\
\hline Upgraded bio-oil (wt.\%) & $49.36 \pm 0.07$ & $45.32 \pm 0.03$ & $49.03 \pm 0.03$ & $46.39 \pm 0.04$ \\
\hline Aqueous phase (wt.\%) & $35.57 \pm 0.07$ & $42.72 \pm 0.01$ & $41.45 \pm 0.01$ & $43.52 \pm 0.03$ \\
\hline Solids (wt.\%) & $0.23 \pm 0.11$ & $0.31 \pm 0.06$ & $0.31 \pm 0.22$ & $0.32 \pm 0.29$ \\
\hline Losses (wt.\%) & $10.54 \pm 0.17$ & $7.10 \pm 0.05$ & $5.65 \pm 0.47$ & $5.90 \pm 0.49$ \\
\hline Hydrogen (wt.\%) & $8.42 \pm 0.07 ; 8.55 \pm 0.07$ & $8.25 \pm 0.01 ; 8.40 \pm 0.01$ & $8.51 \pm 0.31 ; 8.70 \pm 0.28$ & $8.55 \pm 0.31 ; 8.70 \pm 0.28$ \\
\hline Oxygen (wt.\%) & $17.86 \pm 0.05 ; 21.30 \pm 0.01$ & $19.46 \pm 0.15 ; 23.00 \pm 0.14$ & $19.00 \pm 0.91 ; 24.10 \pm 1.13$ & $20.35 \pm 0.01 ; 23.60 \pm 1.41$ \\
\hline Nitrogen (wt.\%) & $0.32 \pm 0.01 ; 0.30 \pm 0.01$ & $0.32 \pm 0.01 ; 0.30 \pm 0.01$ & $0.32 \pm 0.01 ; 0.30 \pm 0.01$ & $0.32 \pm 0.01 ; 0.30 \pm 0.01$ \\
\hline \multicolumn{5}{|l|}{ Physicochemical properties } \\
\hline $\mathrm{H}_{2} \mathrm{O}($ wt. $\%)$ & $4.85 \pm 0.07$ & $5.10 \pm 0.01$ & $7.30 \pm 0.42$ & $5.95 \pm 0.35$ \\
\hline HHV (MJ/kg) & $31.18 \pm 0.08$ & $30.85 \pm 0.02$ & $29.86 \pm 0.26$ & $30.27 \pm 0.31$ \\
\hline
\end{tabular}

The elemental composition of the upgraded bio-oils by the different nickel-based catalysts is presented in Table 2. The concentration of carbon increases in all upgraded bio-oil in comparison to the concentration in the feed (57.31 wt.\% dry basis) [43]. The highest carbon content (73.15 wt.\% dry basis) was obtained applying $\mathrm{Ni} / \mathrm{SiO}_{2}$. The remaining oils upgraded with the other catalysts displaying a 
concentration of around $72.25 \mathrm{wt} . \%$ in dry and $67.38 \mathrm{wt} . \%$ in wet basis, respectively. The hydrogen concentration was slightly higher in the upgraded bio-oils in comparison to the initial feed, while the oxygen content was reduced in comparison to the original beech wood bio-oil (35.84 wt. $\%$ in dry basis). The upgraded bio-oil over $\mathrm{Ni} / \mathrm{SiO}_{2}$ shows the lowest oxygen concentration (17.86 wt.\% dry basis), followed by $\mathrm{NiCu} / \mathrm{SiO}_{2}$ (19.00 wt.\% dry basis), $\mathrm{Ni} / \mathrm{ZrO}_{2}$ (19.46 wt.\% dry basis) and $\mathrm{NiCu} / \mathrm{ZrO}_{2}(20.35$ wt.\% dry basis).

The water content in the upgraded bio-oils was reduced significantly from $26.77 \mathrm{wt} . \%$ in the original feed to values between $4.85 \mathrm{wt} . \%$ and $7.30 \mathrm{wt} . \%$ in the upgraded bio-oils. More than $70 \%$ of the water content in the original oil was removed by the hydrotreatment. The upgraded bio-oil over $\mathrm{Ni} / \mathrm{SiO}_{2}$ showed the lowest water content (4.85 wt.\%), while $\mathrm{NiCu} / \mathrm{SiO}_{2}$ had the highest value (7.30 wt.\%). The opposite was observed for the upgraded aqueous phase. While the upgraded aqueous phase obtained with $\mathrm{Ni} / \mathrm{SiO}_{2}$ showed $74.35 \mathrm{wt} . \%$ of water, the aqueous phase obtained with $\mathrm{NiCu} / \mathrm{SiO}_{2}$ showed $67.15 \mathrm{wt} . \%$ of $\mathrm{H}_{2} \mathrm{O}$ (Table S1). This is because the water removed from the upgraded bio-oils mainly was concentrated in the aqueous phase.

The higher heating value (HHV) also changed by the reactions. In the feedstock, this value was $24.33 \mathrm{MJ} / \mathrm{kg}$, whereas, for the upgraded bio-oils, the HHV increased to values ranging from $29.86 \mathrm{MJ} / \mathrm{kg}$ to $31.18 \mathrm{MJ} / \mathrm{kg}$ in the case of $\mathrm{SiO}_{2}$ supported catalysts. A slight increase in the $\mathrm{pH}$ value was observed, except for the upgraded bio-oil with $\mathrm{Ni} / \mathrm{ZrO}_{2}$. The density of the upgraded bio-oils decreased after the hydrotreatment. Comparing the density of the upgraded bio-oils with the density of the heavy phase, for example, the value was reduced from $1.19 \mathrm{~g} / \mathrm{cm}^{3}$ to values between $1.09 \mathrm{~g} / \mathrm{cm}^{3}$ and $1.12 \mathrm{~g} / \mathrm{cm}^{3}$. The upgraded bio-oil over $\mathrm{NiCu} / \mathrm{SiO}_{2}$ displayed the lowest density $\left(1.09 \mathrm{~g} / \mathrm{cm}^{3}\right)$, while the highest corresponded to $\mathrm{Ni} / \mathrm{ZrO}_{2}\left(1.12 \mathrm{~g} / \mathrm{cm}^{3}\right)$.

Further information regarding the upgraded bio-oils composition was obtained by proton nuclear magnetic resonance $\left({ }^{1} \mathrm{H}-\mathrm{NMR}\right)$, depicted in Figure 3. Table 3 shows the assignment of chemical groups to the integration range of the spectra [44]. The aqueous phases are compared to the light phase (LP) of the feedstock, whereas the upgraded bio-oil is compared to the heavy phase (HP) of the feedstock.
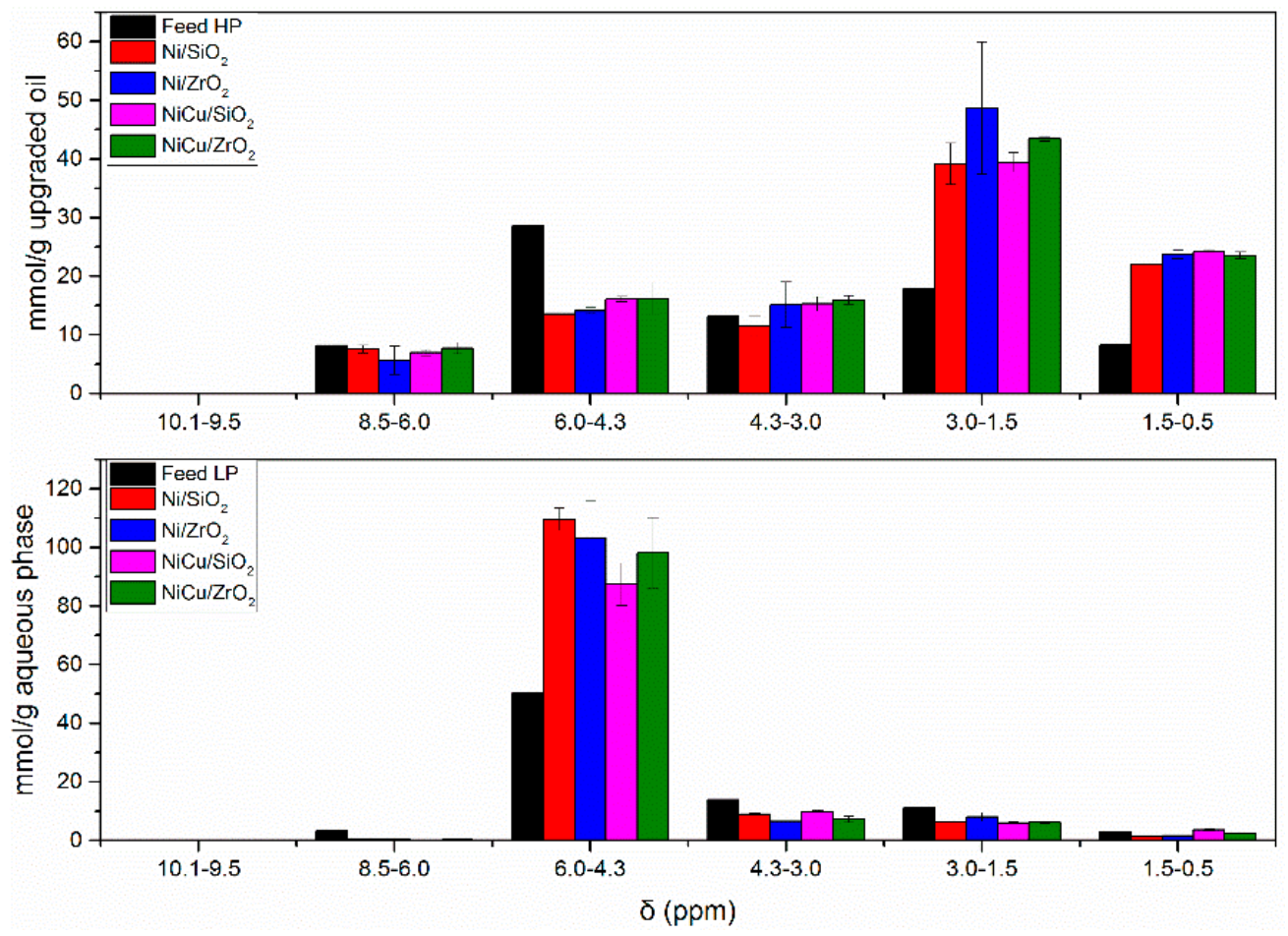

Figure 3. ${ }^{1} \mathrm{H}-\mathrm{NMR}$ spectra integrals of the bio-oil components, HP (top) and LP (bottom), in contrast to the products (upgraded bio-oil and aqueous phase) obtained by different catalysts. 
Table 3. Integration ranges of ${ }^{1} \mathrm{H}-\mathrm{NMR}$ spectra and their corresponding proton assignment [44].

\begin{tabular}{cc}
\hline Integration Range of ${ }^{1} \mathrm{H}-\mathrm{NMR}$ Spectra & Proton Assignment \\
\hline $10.1-9.5$ & Aldehydes \\
$8.5-6.0$ & (Hetero-)aromatics \\
$6.0-4.3$ & Carbohydrates, water, O-H exchanging groups \\
$4.3-3.0$ & Alcohols, ethers, alkenes \\
$3.0-1.5$ & $\alpha$ proton to carboxylic acid or keto-groups, $\alpha$ proton to unsaturated groups \\
$1.5-0.5$ & Alkanes \\
\hline
\end{tabular}

The signals for aldehydes (10.1-9.5 ppm) are very small in the feed, below $0.1 \mathrm{mmol} / \mathrm{g}$ sample in both LP and HP. They were not observed in the upgraded products as they are very reactive even at mild conditions and, therefore, are hydrogenated to alcohols [45]. The main signals for the upgraded bio-oil were found in the region of $\alpha$-protons to carboxylic acid or keto-groups and $\alpha$-protons to unsaturated groups (3.0-1.5 ppm).

The aromatic (8.5-6.0 ppm) were concentrated mostly in the upgraded bio-oil and almost absent in the aqueous phase ( 7.0 versus $0.2 \mathrm{mmol} / \mathrm{g}$ sample on average). No significant differences among catalysts were observed. A slight increasing tendency could be observed for the concentration of alcohols, ethers, and alkenes (4.3-3.0 ppm), although it was not significantly different among all tested catalysts. The concentration of protons in this region was more abundant in the upgraded bio-oil ( $14.5 \mathrm{mmol} / \mathrm{g}$ sample on average) in comparison to the aqueous phase $(8.2 \mathrm{mmol} / \mathrm{g}$ sample on average). The abundance of alkanes (1.5-0.5 ppm) almost triples in comparison to the feed (heavy phase) and was significantly higher in the upgraded bio-oil than in the aqueous phase (23.4 versus $2.2 \mathrm{mmol} / \mathrm{g}$ sample).

The accumulation of water in the aqueous phase is also confirmed by the ${ }^{1} \mathrm{H}-\mathrm{NMR}$ measurements, considering that the main signal obtained for the aqueous phase was found in the carbohydrates, water, and $\mathrm{O}-\mathrm{H}$ exchanging groups $(6.0-4.3 \mathrm{ppm})$. The high concentration of protons in this region is attributed to the removal of water from the bio-oil [46,47], in agreement with Karl-Fisher results. On the other hand, the proton in this region decreases in all upgraded bio-oils, especially for $\mathrm{Ni} / \mathrm{SiO}_{2}$, which produced the upgraded bio-oil with the lowest water concentration (Table 3).

To identify the main compounds in the upgraded bio-oils, as well as to investigate differences in selectivity among the catalysts tested, the upgraded bio-oils were analyzed qualitatively by gas chromatography-mass spectrometer (GC-MS), depicted in Figure 4 and Table 4. The chromatograms of the upgraded bio-oils are discussed in comparison to the chromatograms of the heavy phase (feedstock), available in the Supplementary Material (Figure S3). The chromatograms of the upgraded aqueous phases, as well as the light phase of the feedstock, are also available as Supplementary Material (Figures S3 and S4).

Typical compounds were observed in the upgraded bio-oils, such as carboxylic acids, ketones, phenolic compounds and others [48]. The main reaction pathways identified and later discussed are available in Figure S6.

A variety of ketones, especially but not limited to cyclic forms, were identified in all the upgraded bio-oils, such as 2-pentanone, cyclopentanone, 3-methyl-cyclopentanone, 2-ethyl-cyclohexanone, cycloheptanone and others, in agreement with Boscagli et al. [46] and Ardiyanti et al. [23]. They are attributed as products of sugar conversion and its derivatives.

Aromatic compounds initially present in the feedstock also were observed in the upgrade-oil, such as guaiacol (2-methoxy-phenol), phenol and 4-ethyl-2-methoxy-phenol. Acetic acid also was present in the feedstock as well as in the upgraded products. 


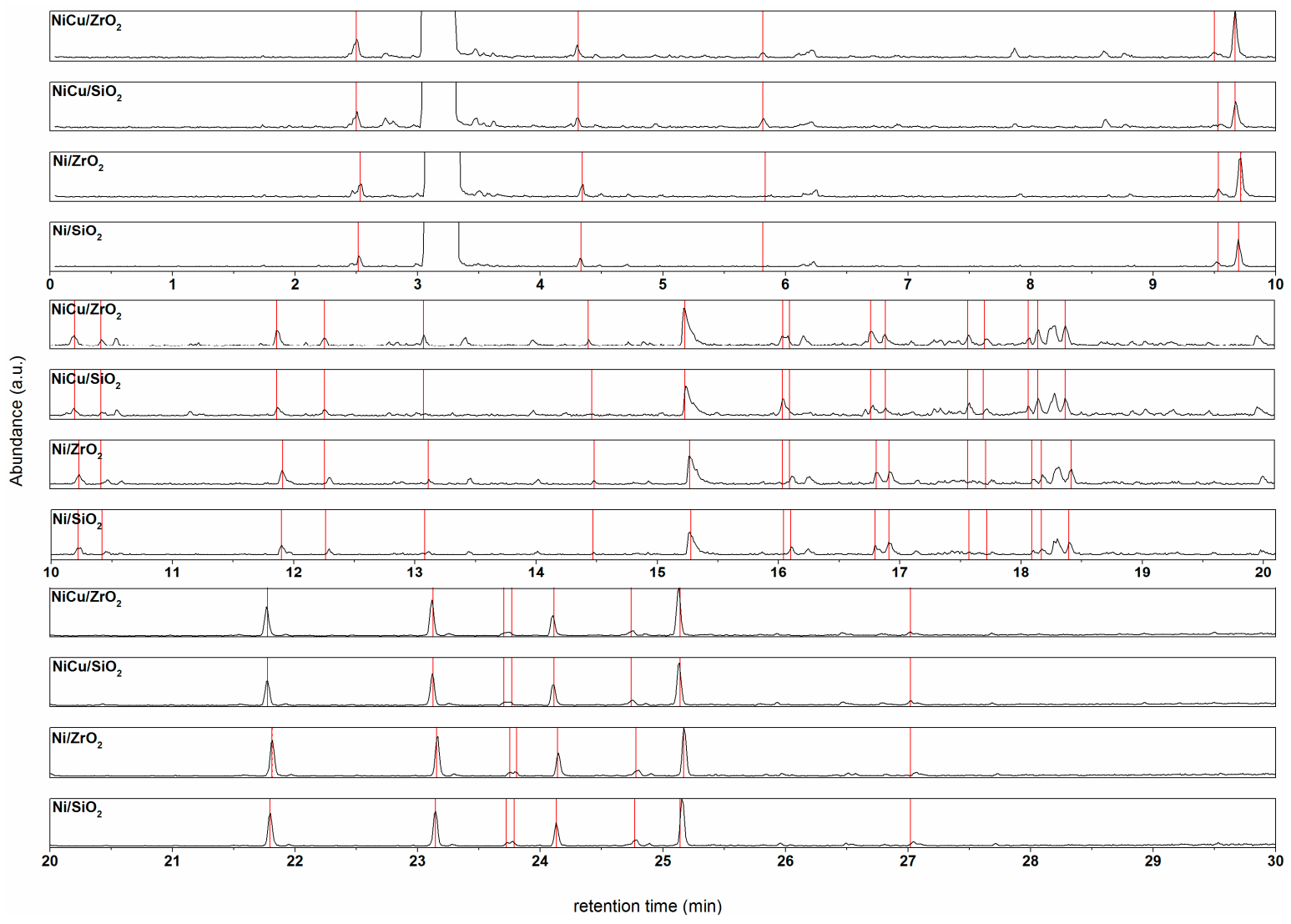

Figure 4. Chromatograms of the upgraded bio-oils over different nickel-based catalysts.

Table 4. Retention time of the main compounds in the upgraded bio-oil identified by GC-MS.

\begin{tabular}{|c|c|}
\hline Retention Time (min) & Compound \\
\hline 2.51 & Acetic acid, methyl ester \\
\hline 4.32 & 2-pentanone \\
\hline 5.82 & 1-propanol \\
\hline 9.46 & Cyclopentanone \\
\hline 9.64 & 2-methyl-cyclopentanone \\
\hline 10.20 & 3-methyl-cyclopentanone \\
\hline 10.42 & (R)-3-methyl-cyclohexanone \\
\hline 11.84 & 2-ethyl-cyclopentanone \\
\hline 12.23 & Cycloheptanone \\
\hline 13.08 & 2-methyl-2-propanol \\
\hline 14.47 & 6-hepten-1-ol \\
\hline 15.23 & Acetic acid \\
\hline 16.04 & Tetrahydro-2-furanmethanol \\
\hline 16.10 & 2,3,4-trimethyl-cyclopent-2-ene-1-one \\
\hline 16.77 & Propanoic acid \\
\hline 16.87 & 2,3-dimethyl-2-cyclopenten-1-one \\
\hline 17.57 & Propylene glycol \\
\hline 18.07 & Dihydro-5-methyl-2 $(3 H)$-furanone \\
\hline 18.13 & 1,2-ethanediol \\
\hline 18.40 & $\gamma$-butyrolactone \\
\hline 19.05 & 3-pentanol \\
\hline 21.74 & 2-methoxy-phenol \\
\hline 23.09 & 2-methoxy-4-methyl-phenol \\
\hline 23.67 & 4-methyl-phenol \\
\hline 23.70 & Phenol \\
\hline 24.07 & 4-ethyl-2-methoxy-phenol \\
\hline 24.72 & 2-ethyl-phenol \\
\hline 25.1 & 2-methoxy-4-propyl-phenol \\
\hline 27.02 & 2-propyl-phenol \\
\hline
\end{tabular}


After the upgrading reaction, compounds initially present in the bio-oil mixtures, such as furfural, were completely converted for all the catalysts tested. The same was observed for eugenol and compounds with GC retention times higher than $30 \mathrm{~min}$, such as vanillin. Although very similar compositions of all upgraded bio-oils, some differences in selectivity were observed for the catalysts. 1-propanol (5.82 $\mathrm{min})$ was observed only in the bio-oils upgraded with bimetallic catalysts, as well as the peak at $16.04 \mathrm{~min}$, attributed to tetrahydro-2-furanmethanol (tetrahydrofurfuryl alcohol), also observed in the bio-oils upgraded with $\mathrm{NiCu}$ catalysts. It shows that furfural is completely hydrogenated to tetrahydrofurfuryl alcohol over these catalysts [49]. Earlier studies observed the selectivity of copper-containing catalysts for furfural hydrogenation, particularly at high temperatures [50]. Furfural also can be converted to cyclopentanone [48,49] and 2-pentanone [8,51], both identified in the products, as well as other cyclopentanones [52].Compounds such as methane, identified in the gas phase and later discussed, also can be derived from furfural conversion; the conversion of furfural to furfuryl alcohol and later to furan leads to methane formation [53]. Furthermore, the peak at $17.57 \mathrm{~min}$, attributed to propylene glycol, was observed only in the upgraded bio-oils as well as in the aqueous phases (Figure S5) upgraded with $\mathrm{NiCu}$ catalysts. Propylene glycol can be obtained from hydrogenation of hydroxyacetone [54], which was converted completely after the HDO reactions (see peak at 12.46 min Figure S3). While copper-containing catalysts seem to favor the production of propylene glycol in comparison to other catalysts [55], nickel catalysts seems to follow a different pathway. Resulting from the C-O bond cleavage of propylene glycol [54], 1-propanol was observed in the oils upgraded with bimetallic catalysts. Furthermore, compounds initially absent in the feedstock, such as 2-methoxy-4-propyl-phenol, resulting from the hydrogenation of the double bond of eugenol, were identified in the upgraded bio-oil [47]. A peak at a retention time of $26.9 \mathrm{~min}$ was observed in the upgraded aqueous phases obtained with bimetallic catalysts, although the identification of the compound was not possible.

Differences among the feed (LP) and upgraded products (aqueous phases), as well as among the products obtained with different catalysts, were observed. For example, 2-methyl-propanol (13.08 min) was observed in all upgraded aqueous phases, except for $\mathrm{NiCu} / \mathrm{SiO}_{2}$. The peak attributed to tetrahydro-2-furanmethanol increased significantly, mainly in the aqueous phases obtained by bimetallic catalysts, in the same way as observed in the upgraded bio-oils. Propanoic acid (16.77 min) was observed for all aqueous phases.

\subsubsection{Hydrogen Consumption and Gaseous Products}

The hydrogen consumption was considered for the evaluation of the different catalysts. $\mathrm{NiCu} / \mathrm{SiO}_{2}$ presented the highest consumption ( $239.3 \mathrm{NL} / \mathrm{kg}$ bio-oil), followed by $\mathrm{NiCu} / \mathrm{ZrO}_{2}$ (201.6 NL/kg bio-oil), $\mathrm{Ni} / \mathrm{SiO}_{2}\left(186.2 \mathrm{NL} / \mathrm{kg}\right.$ bio-oil) and $\mathrm{Ni} / \mathrm{ZrO}_{2}(181.9 \mathrm{NL} / \mathrm{kg}$ bio-oil). Yin et al. [35] reported, higher hydrogenation activity can be seen when adding copper to Ni catalysts, due to changes in the catalytic activity and selectivity, favoring some hydrogenation reactions [56]. The hydrogen consumption can be correlated with the $\mathrm{H} / \mathrm{C}$ molar ratio. A higher $\mathrm{H} / \mathrm{C}$ molar ratio and lower $\mathrm{O} / \mathrm{C}$ molar ratio indicates an upgraded bio-oil with improved properties [15]. The catalysts evaluated resulted in $\mathrm{H} / \mathrm{C}$ ratios between $1.37\left(\mathrm{Ni} / \mathrm{ZrO}_{2}\right)$ to $1.53\left(\mathrm{NiCu} / \mathrm{SiO}_{2}\right)$, showing a tendency between the hydrogen uptake and the $\mathrm{H} / \mathrm{C}$ molar ratio. The same tendency was not observed for the $\mathrm{O} / \mathrm{C}$ ratio. The lowest ratio was observed using $\mathrm{Ni} / \mathrm{SiO}_{2}(0.18)$ whereas the highest was for $\mathrm{NiCu} / \mathrm{ZrO}_{2}$ (0.28). This indicates that a higher consumption of $\mathrm{H}_{2}$ does not reflect in the HDO of the feedstock.

Although a very similar total gas production (Figure 5) was obtained for all tested catalysts, $\mathrm{Ni} / \mathrm{ZrO}_{2}$ showed the highest total gas production $\left(1.06 \mathrm{~mol} / \mathrm{kg}\right.$ bio-oil), followed by $\mathrm{Ni} / \mathrm{SiO}_{2}$ ( $0.99 \mathrm{~mol} / \mathrm{kg}$ bio-oil), $\mathrm{NiCu} / \mathrm{ZrO}_{2}(0.90 \mathrm{~mol} / \mathrm{kg}$ bio-oil $)$ and $\mathrm{NiCu} / \mathrm{SiO}_{2}(0.86 \mathrm{~mol} / \mathrm{kg}$ bio-oil). The total gas production was determined mainly by the production of $\mathrm{CO}_{2}$, the most abundant gas product for all four catalysts, in agreement with other studies $[35,40,41,46]$. Decarboxylation of carboxylic 
acids can result in $\mathrm{CO}_{2}$ formation [46]. Carbon monoxide, methane, and other gases such as propane, propene, ethane and ethene were formed in smaller amounts.

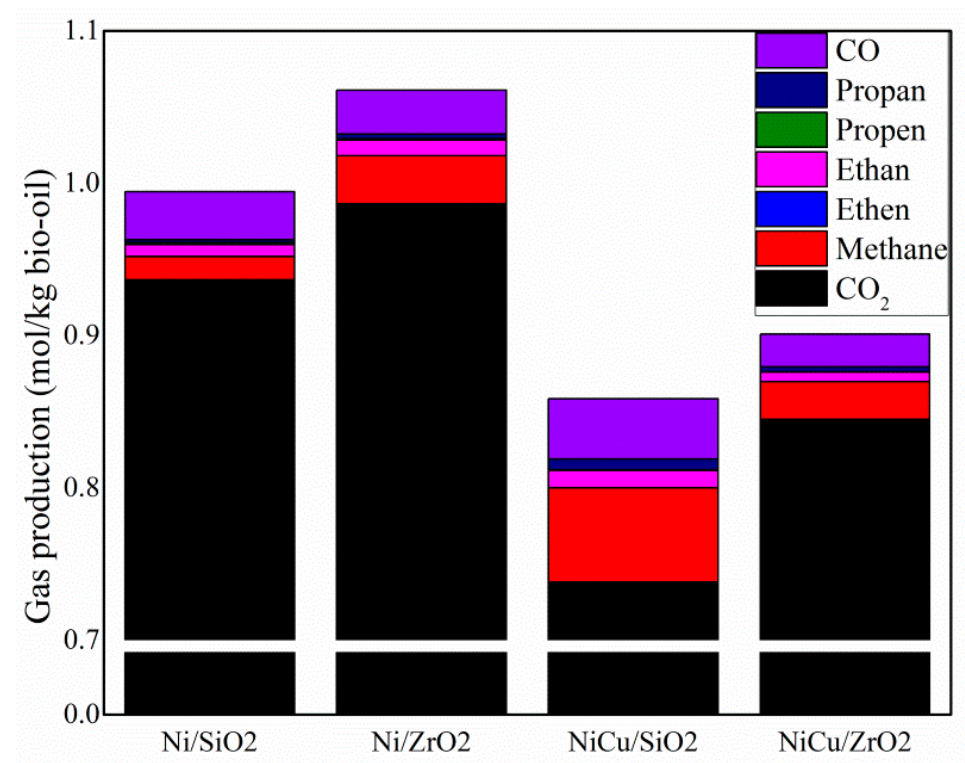

Figure 5. Production and composition of the gas phase for the nickel-based catalysts tested.

Monometallic Ni catalysts produced the highest amount of $\mathrm{CO}_{2}$, followed by $\mathrm{NiCu} / \mathrm{ZrO}_{2}$ and, later, by $\mathrm{NiCu} / \mathrm{SiO}_{2}$. According to Gallakota et al. [14], in an ideal scenario all $\mathrm{C}$ atoms should be converted to hydrocarbons without $\mathrm{CO}_{2}$ formation. Nevertheless, since the total gas production of the four catalysts represented around $4 \mathrm{wt}$.\% (see mass balance Table 2), the produced amounts of $\mathrm{CO}_{2}$ are, in general, quite reduced in these four cases. The formation of $\mathrm{CO}_{2}$ might indicate lower hydrogen consumption [57]. This effect was observed when the $\mathrm{CO}_{2}$ production was compared to the hydrogen consumption - both variables were inversely proportional (Figure S2), as reported by Boscagli et al. [46]. This tendency only was noticed in the $\mathrm{CO}_{2}$ production, but not for the remaining produced gases.

The formation of methane was observed mainly for $\mathrm{NiCu} / \mathrm{SiO}_{2}$. The smallest concentration of methane was obtained for $\mathrm{Ni} / \mathrm{SiO}_{2}$. Methane resulted from the hydrogenation of carbohydrates, acetic acid decomposition, cleavage of $\mathrm{C}-\mathrm{C}$ bonds of alcohols or even from methoxy groups demethylation [57]. It is important to highlight that the higher methane production was observed with $\mathrm{NiCu} / \mathrm{SiO}_{2}$, the catalyst that showed the highest $\mathrm{H}_{2}$ consumption. This is an indication of hydrocracking of the molecules and excessive hydrogen consumption [35,58].

$\mathrm{CO}$ formation was more abundant in the $\mathrm{SiO}_{2}$-supported catalysts. $\mathrm{NiCu} / \mathrm{SiO}_{2}$ displayed the highest amount, followed by $\mathrm{Ni} / \mathrm{SiO}_{2}, \mathrm{Ni} / \mathrm{ZrO}_{2}$ and $\mathrm{NiCu} / \mathrm{ZrO}_{2}$. The formation of $\mathrm{CO}$ can be a result of the $\mathrm{C}-\mathrm{O}$ cleavage of different groups, such as carboxylic acids, aldehydes, and alcohols. The loss of $\mathrm{C}$ via $\mathrm{CO}$ (decarbonylation), is less advantageous than the loss of $\mathrm{CO}_{2}$ (decarboxylation), considering more $\mathrm{O}$ is removed per mole of lost carbon [57].

\subsubsection{Catalysts Characterization}

The spent catalysts were evaluated mainly in terms of metal leaching, XRD, sintering, carbon deposition as well as surface area and composition. Inductively Coupled Plasma Emission Spectroscopy (ICP-OES) was further used to evaluate the metal content present in the upgraded aqueous phases and determine the metal leaching. $\mathrm{Ni} / \mathrm{SiO}_{2}$ presented $0.8 \%$ of $\mathrm{Ni}$ leached while using $\mathrm{Ni} / \mathrm{ZrO}_{2} 0.43 \%$ of $\mathrm{Ni}$ was washed into the aqueous phase. Both $\mathrm{NiCu}$ catalysts showed $0.16 \%$ of $\mathrm{Ni}$ leached while $\mathrm{NiCu} / \mathrm{SiO}_{2}$ and $\mathrm{NiCu} / \mathrm{ZrO}_{2}$ displayed $0.08 \%$ and $0.04 \%$ of $\mathrm{Cu}$ leached, respectively. Similar leaching levels also were found by Boscagli et al. [26] for a reaction at $240{ }^{\circ} \mathrm{C}$ compared 
to a $\mathrm{NiCu} / \mathrm{Al}_{2} \mathrm{O}_{3}$ catalyst. The extent of leaching seems to correlate with the support. The lowest proportions of metals leached were observed in $\mathrm{ZrO}_{2}$-supported catalysts. Reported previously, $\mathrm{ZrO}_{2}$ seems to be stable in the harsh reaction conditions $[28,40,42,59]$. Due to the severity of the HDO reactions, the structure, morphology and texture of the catalysts might be affected [40], therefore, the spent catalysts were analyzed by XRD after the reactions. No significant differences were observed between the X-ray diffraction patterns of the fresh and spent catalysts, except for $\mathrm{NiCu} / \mathrm{ZrO}_{2}$. The small diffractions attributed to $\mathrm{NiO}$ disappeared in the spent catalysts, indicating further nickel reduction. The XRD patterns are available in Figure S1. The crystallite sizes were calculated for the spent catalysts. The crystallite size of $\mathrm{NiCu} / \mathrm{SiO}_{2}$ increased from $21.4 \mathrm{~nm}$ to $43.0 \mathrm{~nm}$ after the reaction. Such an increase in the crystallite size was previously observed [60] and is an indication of sintering, which might result in loss of the catalyst activity [61]. Conversely, the crystallite size of $\mathrm{Ni} / \mathrm{ZrO} 2, \mathrm{Ni} / \mathrm{SiO}_{2}$ and $\mathrm{NiCu} / \mathrm{ZrO}_{2}$ remained in the same range observed for the fresh catalysts. The composition of selected particles was analyzed by EDX (Energy Dispersive X-ray spectroscopy) and the results obtained for the fresh and spent catalysts are presented in Table 5.

Table 5. Composition of selected particles of different Ni-based catalysts (fresh and spent) obtained by EDX.

\begin{tabular}{|c|c|c|c|c|c|c|c|c|c|}
\hline Catalyst & & Ni (wt.\%) & Cu (wt.\%) & Si (wt.\%) & Zr (wt.\%) & C (wt.\%) & S (wt.\%) & Ca (wt.\%) & Fe (wt.\%) \\
\hline \multirow{2}{*}{$\mathrm{Ni} / \mathrm{SiO}_{2}$} & Fresh & 11.2 & - & 38.6 & - & 3.6 & - & - & - \\
\hline & Spent & 7.3 & - & 44.9 & - & 12.1 & 0.2 & - & - \\
\hline \multirow{2}{*}{$\mathrm{Ni} / \mathrm{ZrO}_{2}$} & Fresh & 8.6 & - & - & 60.9 & 6.4 & - & - & - \\
\hline & Spent & 6.3 & 0.7 & - & 45.5 & 26.3 & 0.1 & 0.1 & 1.3 \\
\hline \multirow{2}{*}{$\mathrm{NiCu} / \mathrm{SiO}_{2}$} & Fresh & 30.0 & 2.9 & 29.2 & - & 3.2 & - & - & - \\
\hline & Spent & 26.9 & 2.4 & 18.2 & - & 26.7 & 0.2 & - & - \\
\hline \multirow{2}{*}{$\mathrm{NiCu} / \mathrm{ZrO}_{2}$} & Fresh & 55.8 & 6.3 & - & 20.0 & 4.0 & - & - & - \\
\hline & Spent & 44.0 & 4.5 & - & 16.4 & 24.3 & 0.1 & 0.1 & 0.7 \\
\hline
\end{tabular}

Carbon deposition was observed for all catalysts after HDO, with lower concentration observed in $\mathrm{Ni} / \mathrm{SiO}_{2}$. Poisoning substances, such as sulfur and calcium, were observed near the detection limit in the spent forms. Sulfur appeared in all spent catalysts, whereas calcium and iron were observed only in zirconia-supported catalysts. The Ni proportion over the catalysts' surfaces decreased, attributed mainly to the carbon deposits of higher molecular weight polymerization products [35]. The specific surface areas of the spent catalysts were reduced in comparison to the fresh ones, especially for the silica-supported catalysts. The specific surface area of $\mathrm{Ni} / \mathrm{SiO}_{2}$ was reduced to $46 \mathrm{~m}^{2} / \mathrm{g}$, a sharp reduction in comparison to the original surface area $\left(215 \mathrm{~m}^{2} / \mathrm{g}\right) . \mathrm{NiCu} / \mathrm{SiO}_{2}$ showed a reduction from $156 \mathrm{~m}^{2} / \mathrm{g}$ to $36 \mathrm{~m}^{2} / \mathrm{g}$. It can be attributed to the fact that the pores probably were blocked by carbonaceous deposition. The micropore area of $\mathrm{Ni} / \mathrm{SiO}_{2}$ was reduced to $8 \mathrm{~m}^{2} / \mathrm{g}$, whereas the micropore area of $\mathrm{NiCu} / \mathrm{SiO}_{2}$ was reduced to $3 \mathrm{~m}^{2} / \mathrm{g}$. The reduction in the surface area of the zirconia-supported catalyst was less significant. $\mathrm{Ni} / \mathrm{ZrO}_{2}$ showed a reduction to $57 \mathrm{~m}^{2} / \mathrm{g}$ (original: $65 \mathrm{~m}^{2} / \mathrm{g}$ ), whereas $\mathrm{NiCu} / \mathrm{ZrO}_{2}$ was reduced from 50 to $36 \mathrm{~m}^{2} / \mathrm{g}$. The reduction of the surface area is attributed to deposition of carbon in all cases, as already documented by many authors [41,62-64].

Considering that SEM-EDX (Scanning Electron Microscopy/Energy Dispersive X-ray spectroscopy) provides the elemental mapping of only selected regions [65], further composition analysis was performed measuring the active metals and poisoning substances in the bulk catalyst (Table 6).

Agreeing with EDX results, an increase in the calcium concentration over both zirconia-supported catalysts was observed. Sulfur, considered a very persistent poisoning substance of nickel $[26,66]$, increased in all catalysts tested after the reaction, with slightly lower concentrations at $\mathrm{Ni} / \mathrm{SiO}_{2}$. Interestingly, no differences were observed in the XRD spectra, such as nickel sulfide formation [66]. The concentration of active metals $(\mathrm{Ni}$ and $\mathrm{Cu}$ ) was reduced in the spent forms in comparison to the fresh catalyst. This behavior correlates to the carbon deposition. Accompanying a higher concentration of carbon, which initially is absent in the fresh catalysts, the average concentration of nickel and copper 
in the spent catalyst decreases. Furthermore, leaching also can play a role in the reduction of active metal in the catalyst, as discussed previously. The carbon concentration obtained by elemental analysis shows the same tendencies as observed with the EDX measurements.

Table 6. Metal content and poisoning substances on the catalyst before and after the reaction.

\begin{tabular}{|c|c|c|c|c|c|c|c|}
\hline Catalyst & & $\mathrm{Ca} *(w \mathrm{t} . \%)$ & $S *(w t . \%)$ & $M g *(w t . \%)$ & $\mathrm{Ni}^{*}($ wt.\%) & $\mathrm{Cu} *(w t . \%)$ & $C^{* *}(w t . \%)$ \\
\hline \multirow{2}{*}{$\mathrm{Ni} / \mathrm{SiO}_{2}$} & Fresh & 0.03 & 0.01 & 0.01 & 7.94 & - & - \\
\hline & Spent & 0.03 & 0.12 & 0.01 & 7.05 & 0.01 & 4.2 \\
\hline \multirow{2}{*}{$\mathrm{Ni} / \mathrm{ZrO}_{2}$} & Fresh & 0.01 & 0.01 & - & 8.02 & - & - \\
\hline & Spent & 0.06 & 0.13 & 0.01 & 6.94 & 0.07 & 5.6 \\
\hline \multirow{2}{*}{$\mathrm{NiCu} / \mathrm{SiO}_{2}$} & Fresh & 0.02 & 0.01 & 0.01 & 27.90 & 3.25 & - \\
\hline & Spent & 0.02 & 0.13 & 0.01 & 25.90 & 2.76 & 8.6 \\
\hline \multirow{2}{*}{$\mathrm{NiCu} / \mathrm{ZrO}_{2}$} & Fresh & 0.01 & 0.01 & - & 27.30 & 3.10 & - \\
\hline & Spent & 0.05 & 0.14 & 0.01 & 25.25 & 2.72 & 7.1 \\
\hline
\end{tabular}

${ }^{*}$ Results obtained by ICP-OES. ** Results obtained by elemental analysis.

\subsection{Cycles of HDO and Regeneration: Catalyst and Product Behavior}

$\mathrm{Ni} / \mathrm{SiO}_{2}$ was selected for further consecutive $\mathrm{HDO}$ reactions as soon as the original reactions with the fresh catalyst were carried out. Key parameters were considered for selection of this catalyst for consecutive HDO-regeneration cycles: HDO activity, water and carbon concentration in the upgraded bio-oil, hydrogen consumption as well as solid formation. The upgraded bio-oil obtained with $\mathrm{Ni} / \mathrm{SiO}_{2}$ showed the highest carbon content and the lowest oxygen content in comparison to other catalysts, an indication of the improvement of the oil quality (higher energy density and better chemical stability). Additionally, upgrading with $\mathrm{Ni} / \mathrm{SiO}_{2}$ resulted in an upgraded bio-oil with the lowest water concentration, low hydrogen consumption, lowest amount of solids formed, highest HHV and $\mathrm{pH}$ (Table 2). Finally, the smallest production of methane also was obtained for this catalyst (Figure 5). Therefore, $\mathrm{Ni} / \mathrm{SiO}_{2}$ was selected to carry out the following regeneration steps.

Along the cycles of HDO-regeneration, the catalyst was characterized in the intermediate steps of the process: spent, calcined, and reduced form. Only a small amount of sample was available for characterization, considering that the catalyst needed to be reused in the following experiments. Due to that reason, two techniques which require low sample amounts showing meaningful results were selected to monitor the catalyst along the cycles-SEM-EDX and XRD. The upgraded products were characterized using the same techniques as described previously.

Looking at the SEM-EDX results, it was possible to follow the main changes occurring on the catalyst surface (Figure 6). The fresh catalyst showed a good dispersion of nickel particles over the support surface (Figure S7 fresh a). Along the cycles, sintering of the nickel particles was observed. Specific regions were analyzed by EDX to estimate the composition. While the fresh catalyst mainly was composed of nickel, silica and a low concentration of carbon, the spent catalysts clearly showed a small concentration of sulfur (near the detection limit) located around the nickel particles. Interestingly, in the regions with very low nickel concentration or even absent of nickel, no sulfur was identified. $\mathrm{Al}$ and Fe were also observed in the EDX spectrum, although in very small concentrations (below $0.1 \mathrm{wt.} \%$ ). Aluminum was observed in small concentrations (support composition) but the authors cannot discard the possibility of contamination during the removal of the catalyst from the autoclave (aluminum paste is used to seal the reactor).

Considering that EDX measurements can be made either as element mapping or point analysis, both methods were used. Further compilation of images, as well as the mapping of the catalyst surface along the cycles, is available in the Supplementary Material (Figures S7 and S8 and Table S3). 


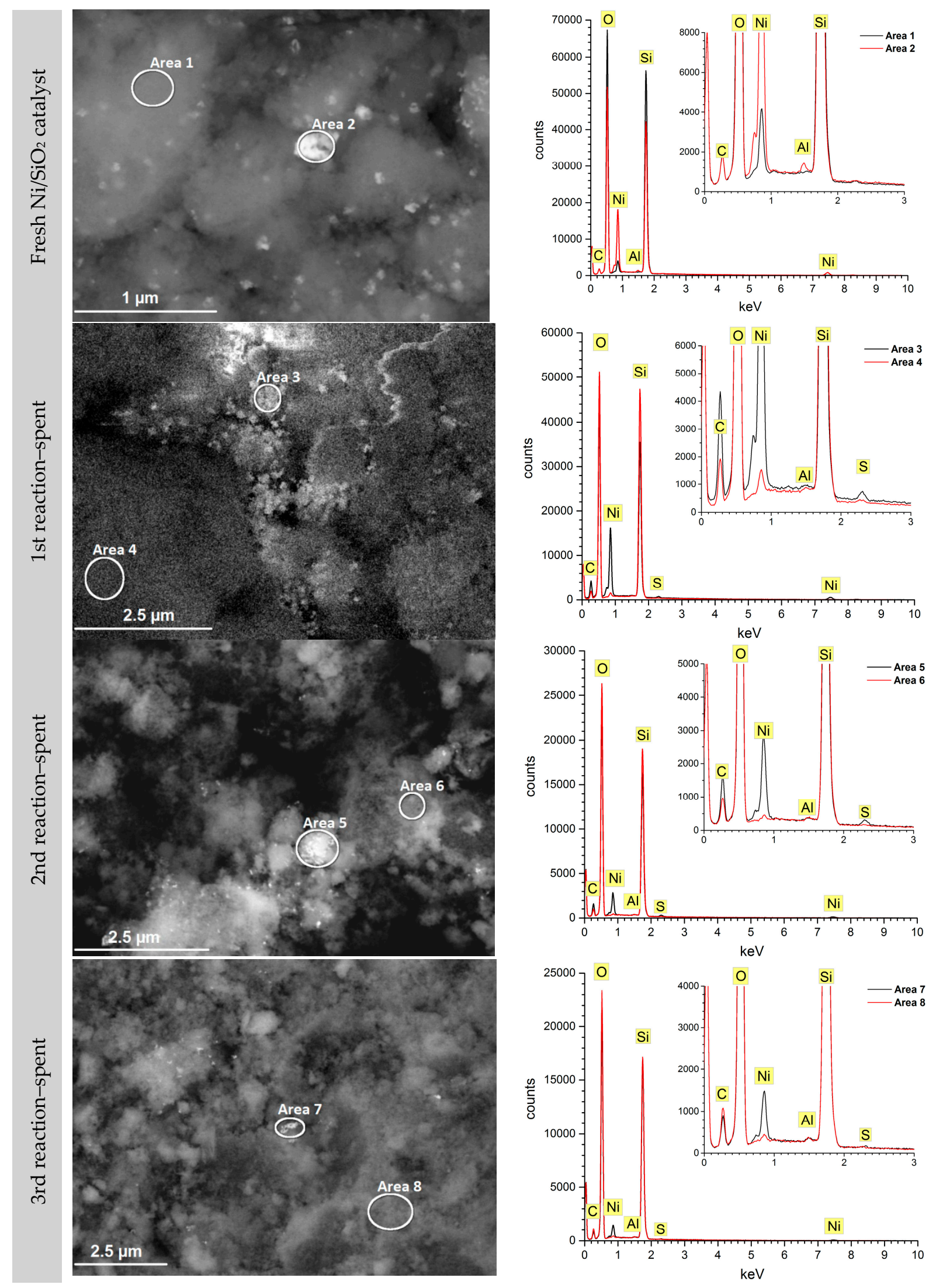

Figure 6. Cont. 

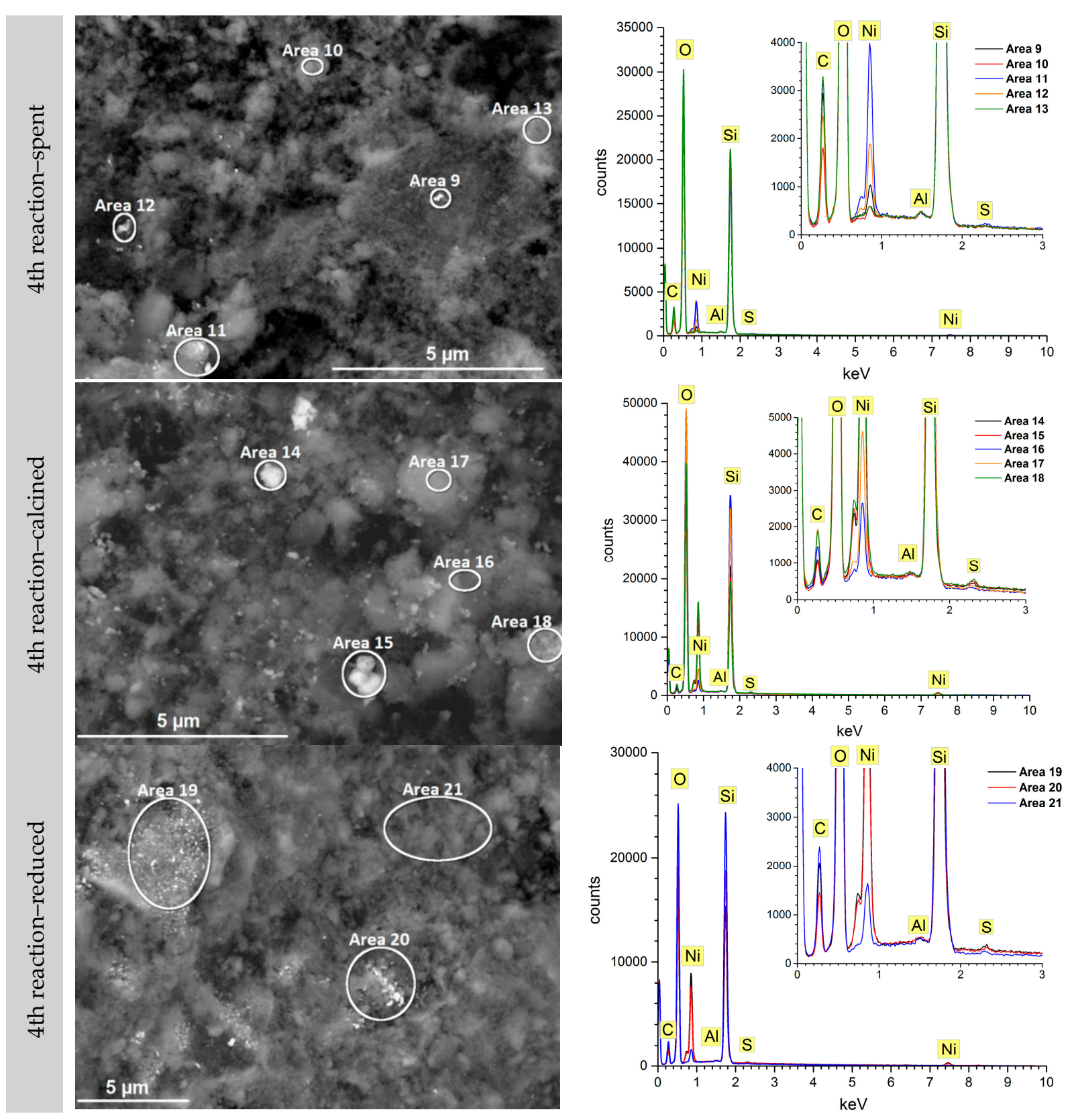

Figure 6. SEM-EDX images and spectra of $\mathrm{Ni} / \mathrm{SiO}_{2}$ along the consecutive cycles.

Following the fourth reaction, the catalyst was analyzed by SEM-EDX in three different situations-spent, after the calcination and, finally, after the reduction step. Although punctual analyses were performed (Table 7), some trends could be observed. Regarding carbon, an expected lower concentration was observed after the calcination step (spectrum 14-16), in comparison to the spent catalyst (spectrum 9-13). Furthermore, the sulfur remained over the reduced catalyst, mainly in the regions with higher nickel concentration, indicating a persistent adsorption. Further structural investigation along the cycles was obtained by XRD and, in this case, the catalyst was analyzed along each new regeneration cycle, in the spent, calcined, and reduced forms (Figure 7). Metallic Ni reflection was observed in the fresh, spent, and reduced catalysts along the consecutive reactions. Due to the calcination step, reflections attributed to $\mathrm{NiO}$ were observed which disappeared after the reduction. Considering the low concentration of sulfur over the spent catalyst surface, reflections attributed to $\mathrm{Ni}_{3} \mathrm{~S}_{2}$ as found by other authors $[26,67,68]$ were not observed, even after the fourth reaction. 
Table 7. SEM-EDX scan composition of selected regions of $\mathrm{Ni} / \mathrm{SiO}_{2}$ over consecutive cycles.

\begin{tabular}{|c|c|c|c|c|}
\hline Spectrum & $C(w t . \%)$ & Si (wt.\%) & S (wt. \%) & $\mathrm{Ni}(w t . \%)$ \\
\hline 1-Fresh $\mathrm{Ni} / \mathrm{SiO}_{2}$ & 4.1 & 41.5 & - & 3.1 \\
\hline 2-Fresh Ni/SiO & 2.6 & 24.9 & - & 44.9 \\
\hline 3-1st reaction (spent) & 8.4 & 24.5 & 0.3 & 37.1 \\
\hline 4-1st reaction (spent) & 6.0 & 42.8 & - & 1.2 \\
\hline 5-2nd reaction (spent) & 8.2 & 29.3 & 0.4 & 19.8 \\
\hline $6-2$ nd reaction (spent) & 5.8 & 38.6 & $<0.1$ & 0.6 \\
\hline 7-3rd reaction (spent) & 5.5 & 35.4 & 0.1 & 13.6 \\
\hline 8-3rd reaction (spent) & 7.61 & 38.1 & - & - \\
\hline 9-4th reaction (spent) & 14.1 & 32.5 & - & 4.2 \\
\hline $10-4$ th reaction (spent) & 10.1 & 37.0 & - & 1.0 \\
\hline 11-4th reaction (spent) & 14.2 & 27.5 & 0.1 & 17.4 \\
\hline $12-4$ th reaction (spent) & 12.3 & 32.8 & - & 7.7 \\
\hline 13-4th reaction (spent) & 14.7 & 32.8 & - & 0.7 \\
\hline $14-4$ th reaction (calcined) & 2.4 & 22.3 & 0.1 & 41.6 \\
\hline 15-4th reaction (calcined) & 2.3 & 21.0 & 0.2 & 45.2 \\
\hline $16-4$ th reaction (calcined) & 4.6 & 38.7 & $<0.1$ & 1.4 \\
\hline 17-4th reaction (calcined) & 5.7 & 34.7 & 0.1 & 7.1 \\
\hline $18-4$ th reaction (calcined) & 4.5 & 20.6 & 0.3 & 37.5 \\
\hline 19-4th reaction (reduced) & 9.1 & 23.6 & 0.2 & 40.4 \\
\hline $20-4$ th reaction (reduced) & 6.8 & 28.9 & 0.2 & 33.8 \\
\hline $21-4$ th reaction (reduced) & 12.6 & 37.7 & 0.1 & 5.0 \\
\hline
\end{tabular}

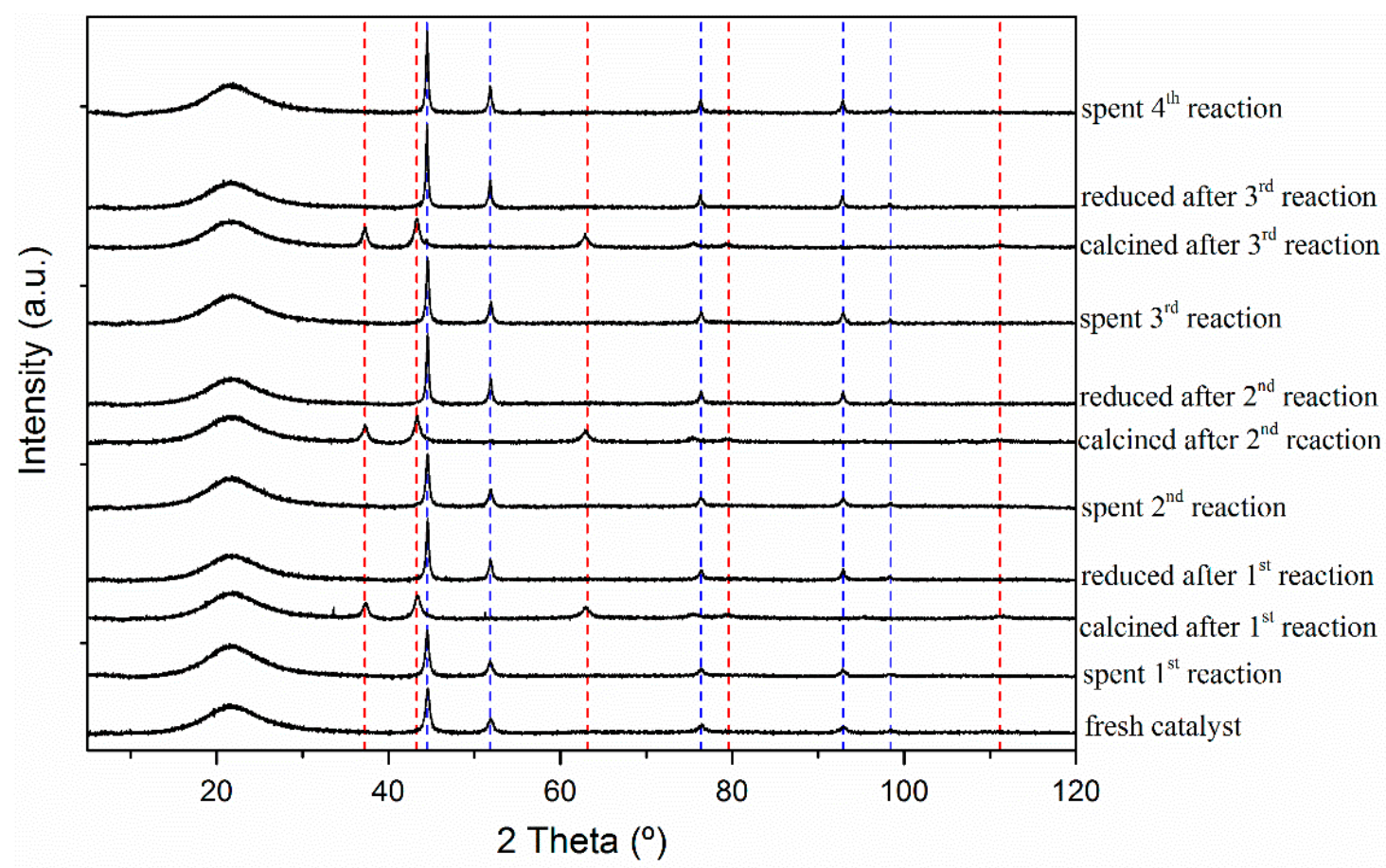

Figure 7. $\mathrm{XRD}$ patterns of $\mathrm{Ni} / \mathrm{SiO}_{2}$ catalyst along consecutive reactions and regeneration steps. Dashed blue lines refer to $\mathrm{Ni}$ and dashed red lines refer to $\mathrm{NiO}$.

An increase in the crystallite sizes could be observed, as also identified by other authors [26]. $\mathrm{Ni} / \mathrm{SiO}_{2}$ showed initially a crystallite size of $17.7 \mathrm{~nm}$. Following subsequent regenerations, the crystallite size reached $37.3 \mathrm{~nm}$ (fourth reaction), due to particle sintering [45], in agreement with the SEM-EDX observations.

Due to the small amount of sample available, the BET surface area was measured only after the fourth reaction (spent catalyst). The original catalyst had a surface area of $215 \mathrm{~m}^{2} / \mathrm{g}$ of catalyst, reduced to $46 \mathrm{~m}^{2} / \mathrm{g}$ after the first reaction and later to $39 \mathrm{~m}^{2} / \mathrm{g}$ after the fourth reaction (spent catalyst), 
slightly lower compared to the first use. Furthermore, the amount of nickel leached to the light phase was calculated. It could be noticed that along the cycles the amount of nickel leached was being reduced as follows: during the 1st reaction $0.8 \%$ of nickel was leached, followed by $0.6 \%$ in the 2 nd, $0.12 \%$ in the 3 rd reaction and, finally, in the 4 th only $0.10 \%$ of nickel was leached.

The physicochemical properties of the upgraded bio-oils over consecutive reactions also were determined (Table 8). The carbon content remained above $72 \mathrm{wt} . \%$, although a slight decrease was observed. The water concentration slightly increased after the second reaction, remaining in the same range over the following reactions (around $5.4 \mathrm{wt} . \%$ ). The HHV and $\mathrm{pH}$ remained in the same range as observed in the reaction performed with the original catalyst. The oxygen concentration increased after the third reaction, reaching $20.35 \mathrm{wt}$.\% after the fourth reuse of the catalyst. Similar tendencies were found by Boscagli et al. [26] evaluating the performance of regenerated catalysts, although, in their study, only one regeneration was considered and a different catalyst $\left(\mathrm{NiCu} / \mathrm{Al}_{2} \mathrm{O}_{3}\right)$ was used. As the number of consecutive reactions increased, the hydrogen consumption decreased, mainly between the first and second reuse. A reduction of $17.18 \%$ in the consumption of hydrogen between the original reaction and the first regeneration, $6.28 \%$ between the first and the second, and just $0.66 \%$ between the second and third regenerations was observed. The lower consumption of hydrogen indicates a decline in the hydrotreatment activity, which can be a result of the sintering, leaching and due to the poisoning substances [61] observed by XRD, ICP-OES and EDX measurements.

Table 8. Physicochemical properties, elemental analysis (in dry basis) of the upgraded bio-oil, hydrogen consumption and total gas production over consecutive HDO reactions and catalyst regeneration.

\begin{tabular}{ccccc}
\hline Property & 1st Reaction & 2nd Reaction & 3rd Reaction & 4th Reaction \\
\hline Carbon (wt.\%) & 73.15 & 73.54 & 72.37 & 72.15 \\
Hydrogen (wt.\%) & 8.42 & 8.25 & 8.51 & 8.55 \\
Oxygen (wt.\%) & 17.86 & 17.74 & 19.00 & 20.35 \\
Nitrogen (wt.\%) & 0.32 & 0.32 & 0.32 & 0.32 \\
$\mathbf{H}_{\mathbf{2}} \mathbf{O}(\mathbf{w t .} \%)$ & 4.85 & 5.4 & 5.5 & 5.3 \\
HHV (MJ/kg) & 31.18 & 30.92 & 31.11 & 31.26 \\
pH value & 3.6 & 2.8 & 3.5 & 3.4 \\
$\mathbf{H}_{\mathbf{2}}$ consumption (NL/kg) & 186.21 & 154.22 & 144.53 & 143.58 \\
Gas production (mol/kg) & 0.99 & 1.23 & 1.31 & 1.35 \\
\hline
\end{tabular}

Furthermore, as the number of consecutive reactions increased, higher amounts of $\mathrm{CO}_{2}$ were produced (Figure 8). Discussed previously, the consumption of hydrogen seems to be inversely proportional to the amount of $\mathrm{CO}_{2}$ produced; Additionally, as the number of consecutive reactions increased, the higher the amounts of $\mathrm{CO}$, propene, ethane and ethene were produced, although less significant in comparison to $\mathrm{CO}_{2}$. Methane remained constant along the cycles.

The changes over consecutive reactions also were monitored by ${ }^{1} \mathrm{H}-\mathrm{NMR}$ (Figure 9). Some trends observed for the original reaction also were observed along the cycles. The signal for aldehydes (10.1-9.5 ppm), already absent in the first reaction due to its high reactivity at low temperatures [45], was not observed in any of the phases for all regeneration stages. The highest signal for the upgraded bio-oil was found in the $\alpha$ protons to unsaturated, carboxylic acids and keto-groups (3.0-1.5 ppm) while, for the aqueous phase, it was in the water, O-H exchanging and carbohydrate groups (6.0-4.3 ppm). Aromatics (8.5-6.0 ppm) mostly were concentrated in the upgraded bio-oil and almost absent in the aqueous phase $(8.3 \mathrm{mmol} / \mathrm{g}$ sample versus $0.2 \mathrm{mmol} / \mathrm{g}$ sample on average). Alkenes, alcohols, and ethers (4.3-3.0 ppm) were concentrated in the upgraded bio-oil $(10.6 \mathrm{mmol} / \mathrm{g}$ sample versus $6.3 \mathrm{mmol} / \mathrm{g}$ in the aqueous phase on average). The same was observed for alkanes (1.5-0.5 ppm), $22.3 \mathrm{mmol} / \mathrm{g}$ bio-oil versus $1.1 \mathrm{mmol} / \mathrm{g}$ aqueous phase on average. It could be seen that the concentration of aromatics remained similar along the reactions. The values also were similar as observed for the feedstock (HP). A similar trend was observed for the carbohydrates, water, and O-H exchanging groups. The increase in this region can be attributed to the higher water concentration in 
the upgraded bio-oils, as well as a lower conversion of compounds belonging to this region. As the number of reactions increased, the concentration of alcohols, ether and alkenes in the upgraded bio-oils decreased. The $\alpha$ proton to unsaturated groups in the upgraded bio-oils was much higher in comparison to the feedstock. An increase of protons was observed in the first reaction, dropping in the following reactions. Alkanes were also in higher concentration compared to the feedstock and the values were quite similar among all the reactions. Conversely, within the aqueous phase, the opposite tendency was observed for the carbohydrates, water and $\mathrm{O}-\mathrm{H}$ exchanging groups. A decline along the regenerations was seen, probably due to the increase of the water content in the upgraded bio-oil (Figure 9). The signal for alcohols, ethers and alkenes also dropped, from $8.7 \mathrm{mmol} / \mathrm{g}$ after the first reaction to $5.2 \mathrm{mmol} / \mathrm{g}$ after the fourth regeneration. The signals for $\alpha$ proton to carboxylic acid or keto-groups, $\alpha$ proton to unsaturated groups, and for alkanes displayed a very small reduction after each reuse of the catalyst.

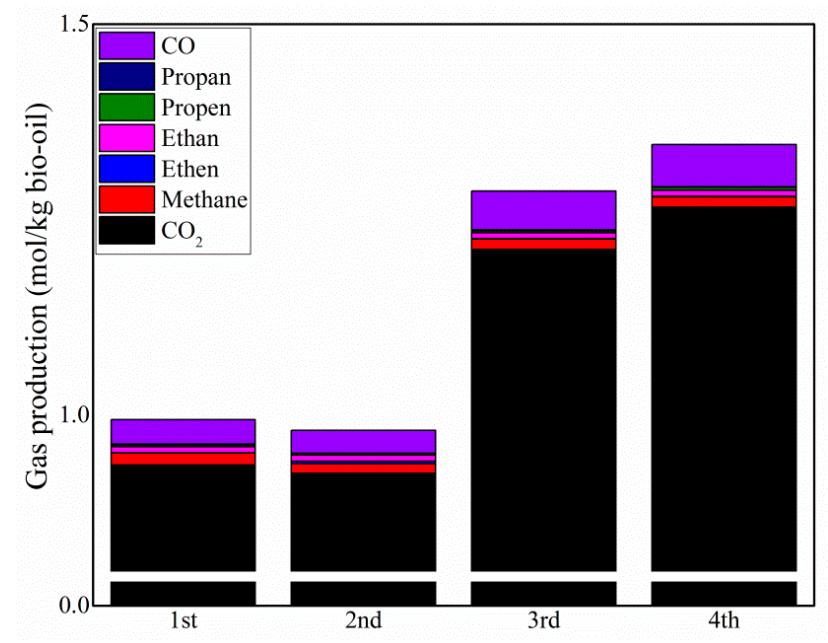

Figure 8. Production and composition of the gas phase obtained for the cycles of hydrotreatmentregeneration.

Further qualitative investigation was performed with GC-MS (Figure 10). The composition of the upgraded bio-oils along the cycles was very similar, although some changes could be observed. The intensity of the peaks attributed to cycloheptanone (12.23 $\mathrm{min}$ ) and 2-methyl-2-propanol (13.08 $\mathrm{min})$ was reduced along the cycles. The same was observed for two more substances: dihydro-5-methyl-2-(3H)-furanone was being reduced until disappeared in the fourth reaction while a visible reduction in the $\gamma$-butyrolactone peak ( $18.4 \mathrm{~min})$ was visible.

The dehydration of C6 sugars, such as glucose, results in compounds such as hydroxymethylfurfural [69]. The following conversion of hydroxymethylfurfural resulted in 5-(Hydroxymethyl)dihydro-2(3H)-furanone which can be further converted to $\gamma$-valerolactone (Dihydro-5-methyl-2(3H)-furanone) through hydrogenation and direct deoxygenation [70]. Conversely, $\gamma$-butyrolactone is obtained through hydrogenation of 2(5H)-furanone [70]. These sugar derivative compounds then can be further converted to ketones and alcohols [28,69]. Based on these results, a correlation between ${ }^{1} \mathrm{H}-\mathrm{NMR}$ and GC-MS could be proposed to explain these findings: Considering the higher signal obtained for the protons belonging to the carbohydrates, water and O-H exchanging groups, it can be assumed that the upgraded bio-oils along the cycles showed higher concentration of not just of water, but possibly also sugars, in comparison to the first reaction. Furthermore, based on the lower intensity of the GC-MS peaks of sugar derivative compounds, such as $\gamma$-valerolactone, $\gamma$-butyrolactone as well as 2-methyl-2-propanol, it is assumed that the conversion of sugars along the upgrading cycles is reduced. The peak intensity of 2-ethyl-cyclopentanone in the light phases (Figure S5) is also reduced along the cycles. It also is evidence of lower conversion of sugars along the 
cycles, considering that this compound can be obtained from a compound with similar structure to furfural [71].
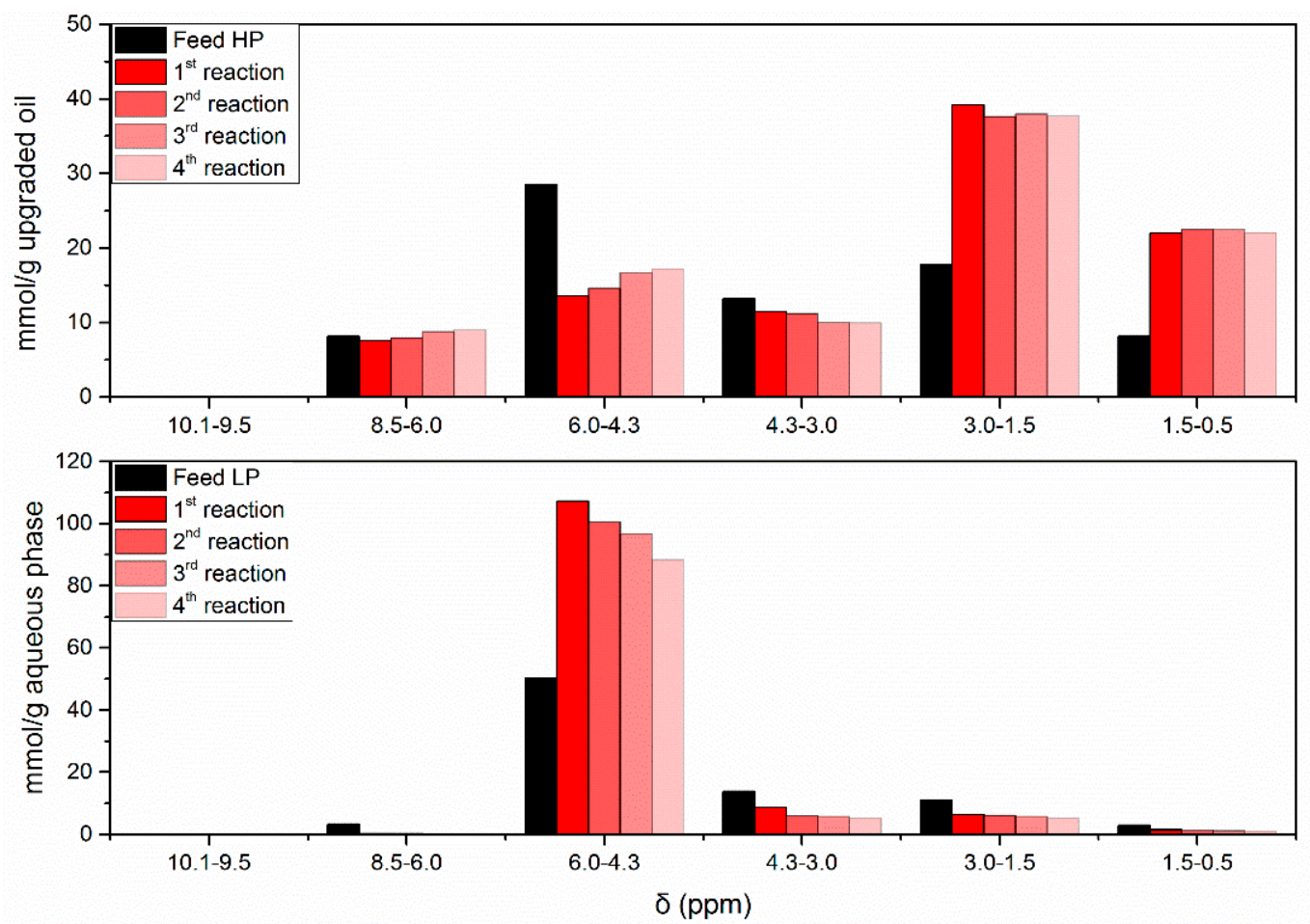

Figure 9. ${ }^{1} \mathrm{H}-\mathrm{NMR}$ spectra integrals of upgraded bio-oil and HP (top) and aqueous phase and LP (bottom) along the HDO-regeneration cycles.

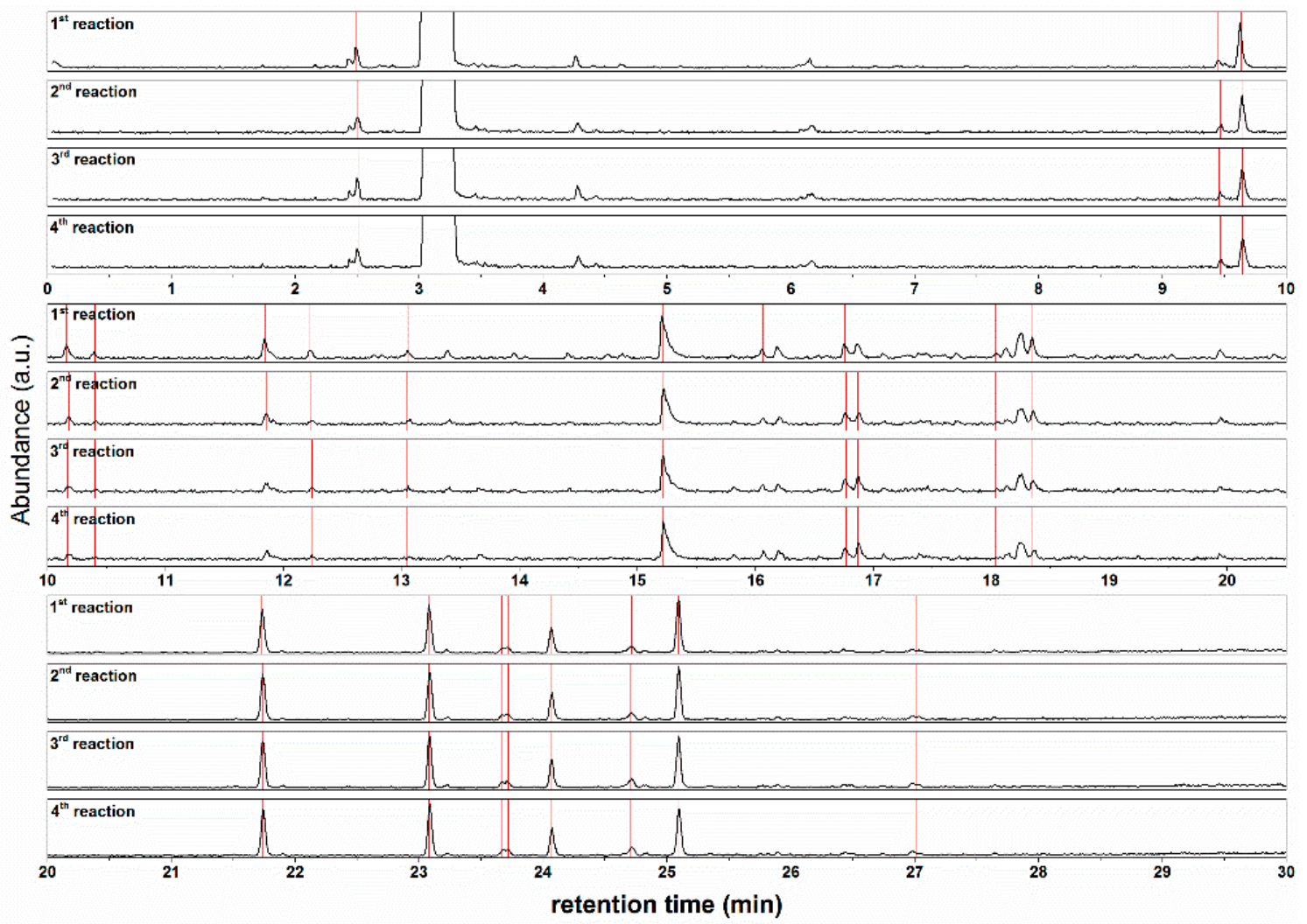

Figure 10. GC-MS upgraded bio-oil along the regeneration cycles. 


\section{Discussion}

The synthesis and evaluation of nickel-based catalysts showed differences among the catalysts evaluated. The temperature programmed reduction $\left(\mathrm{H}_{2}\right.$-TPR) showed that the catalysts, with the addition of copper as a promoter and higher loading of nickel, had lowered the reduction temperature of nickel oxides, which is in agreement with previous studies [30,38].

The evaluation of the catalysts for hydrodeoxygenation (HDO) reactions showed that upgraded bio-oil obtained with $\mathrm{Ni} / \mathrm{SiO}_{2}$ showed the best properties in terms of low oxygen concentration, low water concentration and high HHV. The higher HDO activity for this catalyst can be correlated with its higher surface area in comparison to the other catalysts tested in this study, which could be beneficial to increase the dispersion of the active components, resulting in a more active catalyst $[20,64]$. Coincidently, the $\mathrm{ZrO}_{2}$-supported catalysts showed a lower HDO activity, which might be attributed to the lower surface area of this support [42]. Similar to the current study's findings, Dongil et al. [24] observed lower $\mathrm{HDO}$ activity for $\mathrm{NiCu}$ catalysts in comparison to monometallic Ni catalysts. The authors attributed the lower guaiacol $\mathrm{HDO}$ to the larger particle size, the presence of $\mathrm{NiO}$ particles as well as to copper particles located at the nickel active sites. Furthermore, a higher crystallite size of bimetallic catalysts, as observed for both $\mathrm{NiCu}$ catalysts, also might play a role in the lower HDO activity; the higher crystallite size decreases the number of step/corner sites, which, according to Mortensen et al. [15], are more active for breaking C-O bonds.

Coke formation is another important parameter for the selection of the catalyst. Observed for both $\mathrm{Ni} / \mathrm{SiO}_{2}$ and $\mathrm{NiCu} / \mathrm{SiO}_{2}$, the volume of the micropores was reduced significantly after the reactions. Coke is known for blocking the pores, covering the catalyst active sites, resulting in partial or even complete loss of activity [61], therefore, it is considered one of the main causes of deactivation in HDO reactions $[8,15,28]$. Considering that the catalyst acidity is connected directly to coke formation [8], the lower coke formation observed with $\mathrm{Ni} / \mathrm{SiO}_{2}$ could be related to the low acidity of silica [28]. Due to the amphoteric nature of $\mathrm{ZrO}_{2}$, reduced coke formation would be expected [28]; However, $\mathrm{SiO}_{2}$ was more resistant to coke formation. The addition of $\mathrm{Cu}$ also seems to contribute to the slightly higher amount of coke deposited on the bimetallic catalysts. Stated by Zhang et al. [42], the addition of copper increases the acidity of the catalyst, which can result in higher coke deposition [27], as observed. Hence, the lowest coke deposition observed for $\mathrm{Ni} / \mathrm{SiO}_{2}$ can be related to the lower acidity compared to $\mathrm{NiCu} / \mathrm{SiO}_{2}$ and higher resistance of $\mathrm{SiO}_{2}$ in comparison to $\mathrm{ZrO}_{2}$.

Reactive compounds, such as aldehydes, were converted completely after the upgrading. The reduction of these very reactive compounds results in a more stable oil $[15,29]$. The lower conversion of aromatic compounds over all the catalysts evaluated also is interesting; if further upgrading is intended, aiming at fuel production, the presence of aromatic compounds could result in a high octane number gasoline [29].

Different selectivity among mono and bimetallic catalysts was attributed mostly to the addition of copper [69], with a minor contribution of nickel loading [22]. Furfural, also a very reactive compound [72], mainly seemed to be hydrogenated to tetrahydrofurfuryl alcohol over $\mathrm{NiCu}$ catalysts. Additionally, the presence of propylene glycol leads to the conclusion that hydroxyacetone was mainly hydrogenated to this compound over bimetallic catalysts. Concurring with other authors, the addition of copper seems to increase the hydrogenation [24], increasing the hydrogen consumption. Furthermore, the higher hydrogen consumption observed for $\mathrm{NiCu}$ catalysts is in agreement with literature $[21,23]$ giving evidence that the addition of a second metal can increase the hydrogenation activity of the catalyst [69]. Stated by Mortensen et al. [15], the H/C and O/C is used to evaluate the quality of the upgraded product. A higher $\mathrm{H} / \mathrm{C}$ ratio is intended, whereas a lower $\mathrm{O} / \mathrm{C}$ ratio is desired. In this case, it was observed that the higher $\mathrm{H} / \mathrm{C}$ ratio for $\mathrm{NiCu} / \mathrm{SiO}_{2}$ agrees with the higher consumption of $\mathrm{H}_{2}$ observed for this catalyst, but it was not reflected in the $\mathrm{O} / \mathrm{C}$ ratio. The lowest $\mathrm{O} / \mathrm{C}$ was obtained for $\mathrm{Ni} / \mathrm{SiO}_{2}(0.18)$, being much lower in comparison to the $\mathrm{O} / \mathrm{C}$ ratio of the feed $(0.47)$. It is important to note higher hydrogenation results in higher consumption of hydrogen $[57,73]$, but it is not necessarily reflected in the reduction of the oxygen content. Moreover, the higher consumption of 
hydrogen can also result in higher methane formation [35], considering that during the hydrocracking the consumption of hydrogen is higher compared to hydrotreating [74]. This behavior was observed for $\mathrm{NiCu} / \mathrm{SiO}_{2}$. The catalyst showed not just the higher hydrogen consumption, but also a higher methane formation. The desired catalyst should be able to remove the larger amount of oxygen with minimal hydrogen consumption [24] as hydrogen consumption, bio-oil yield and catalyst deactivation are among the most important parameters to be considered in the $\mathrm{HDO}$ process [75]. $\mathrm{Ni} / \mathrm{SiO}_{2}$, therefore, was considered the more appropriate catalyst in terms of $\mathrm{H}_{2}$ consumption and $\mathrm{HDO}$ activity.

After the reaction, compounds such as calcium (only over $\mathrm{ZrO}_{2}$ ) and sulfur were observed on the spent catalysts by two different analytical techniques, Inductively Coupled Plasma Emission Spectroscopy (ICP-OES) and Scanning Electron Microscopy/Energy Dispersive X-ray spectroscopy (SEM-EDX). Calcium, observed in higher concentrations in comparison to sulfur over the zirconia-supported catalysts, on the one hand acts as a poisoning agent, reducing the mobility and re-dispersion of the active metal centers over the support and, on the other hand, can reduce sintering, due to the reduction in the atom mobility, resistance to dissociation and migration [61].

Despite the detection of sulfur on the catalyst's surface, structural changes were not observed after the reactions by Powder XRD, as observed in previous investigations. Mortensen et al. [66] observed a reflection at approximately $2 \theta=45.2^{\circ}$, attributed to NiS during the evaluation of the influence of sulfur over the conversion of guaiacol with $\mathrm{Ni} / \mathrm{ZrO}_{2}$. Boscagli et al. [26] observed the formation of $\mathrm{Ni}_{3} \mathrm{~S}_{2}$, which was persistent to regeneration and changed the catalyst structure. The concentration of sulfur in the feed, in this case, varies significantly in both works. While Mortensen et al. used a model mixture containing $0.05 \mathrm{wt} . \%$ of sulfur, Boscagli et al. used feedstocks with a higher concentration of sulfur (light bio-oil phase with $0.05 \mathrm{wt} . \%$ of sulfur and straw bio-oil obtained at $450{ }^{\circ} \mathrm{C}$ with $0.3 \mathrm{wt} . \%$ of sulfur). The high concentration of sulfur resulted in a spent catalyst with a much higher concentration of sulfur on the catalyst (0.6-2.0 wt.\%, SEM-EDX), in comparison to the current study's findings (feed sulfur concentration $=0.012 \mathrm{wt} . \%$ and spent catalysts $\leq 0.1-0.4 \mathrm{wt} . \%, \mathrm{SEM}-\mathrm{EDX}$ ). Even without structural changes, sulfur is one of the most persistent poisons for nickel catalysts. It is irreversibly chemisorbed and responsible for blocking the reaction-adsorption active site, modifying electronically the neighbor atom of metals and, thereby, reducing the ability to adsorb and dissociate $\mathrm{H}_{2}$, at the same time influencing the diffusion or reactants, blocking their contact with the active site [61].

Along with the consecutive reactions with $\mathrm{Ni} / \mathrm{SiO}_{2}$, comparable carbon and hydrogen concentrations and a slightly higher oxygen concentration was observed in the upgraded bio-oils. The oxygen concentration reached $20.34 \mathrm{wt} . \%$ after the fourth reaction. It was higher compared to the first reaction (17.86 wt.\%) but still much lower compared to the feed (35.84 wt.\%, dry basis). It gives evidence of a low rate of deactivation and the possibility to reuse the catalyst. The increase in the oxygen concentration can be correlated with the reduction in the $\mathrm{H}_{2}$ uptake, in agreement with lower $\mathrm{HDO}$ activity of $\mathrm{Ni} / \mathrm{SiO}_{2}$ in comparison to the fresh catalyst [76]. The current authors assumed that the reduced activity can be correlated mainly to sintering, poisoning and coke deposition (although easily removed during the calcination step), as the leaching was negligible. The crystallite size increased over the cycles in the same proportion that the HDO activity was reduced along the consecutive reactions. The fresh catalyst showed a crystallite size of $17.7 \mathrm{~nm}$, reaching $37.3 \mathrm{~nm}$ after the fourth reuse. Thus, the number of active surfaces available were reduced with the increase of the crystallite size [61]. Furthermore, the lower $\mathrm{H}_{2}$ uptake can also result in a higher amount of $\mathrm{CO}_{2}$ formation, as observed along the cycles, considering the higher the hydrogen uptake, the lower the $\mathrm{CO}_{2}$ production [46]. Curiously, the sulfur concentration remained approximately constant along the cycles. Furthermore, no differences were observed in the XRD diffractions. The current authors concluded that sulfur was strongly adsorbed on the catalyst, affecting surface-sensitive reactions, resulting only in partial loss of activity of the catalytic surface [61].

The results obtained by ${ }^{1} \mathrm{H}-\mathrm{NMR}$ showed that the concentration of protons in the region related to water and carbohydrates increased along the cycles in the upgraded bio-oils. Moreover, the gas chromatography-mass spectrometer (GC-MS), showed that the peak of some sugar derivatives became 
smaller over the consecutive cycles. It was assumed that the catalytic conversion of sugars was possibly affected by the lower activity of $\mathrm{Ni} / \mathrm{SiO}_{2}$ along the cycles. This assumption corroborates the results of GC-MS, from which the intensity of sugar derivative compounds ( $\gamma$-valerolactone $\gamma$-butyrolactone 2-ethyl-cyclopentanone 2-methyl-2-propanol) have been reduced as the number of cycles increased. Considering the assumption that the conversion of sugars through hydrogenation is reduced with the increase in the number of consecutive reactions, higher amounts of coke formation could be expected, considering that the thermal polymerization of the sugar fraction can lead to increased char deposition $[35,46,77]$ over the cycles. The results of SEM-EDX showed a slightly higher carbon deposition over the spent catalyst after the fourth reaction.

Since poisoning substances might affect some specific reactions [61], the investigation of model compound conversions as well as the effect of poisonings, over single compounds, could contribute to the understanding of the selectivity changes observed along the cycles. Considering the difficulty for regeneration of sulfur-poisoned catalysts, due to the harsh conditions required (700 ${ }^{\circ} \mathrm{C}$ in steam) [61], its influence over the conversion of model compounds should be investigated in detail. Since deactivation mechanisms are difficult to be monitored in batch experiments [66], continuously operated reactors are more appropriate for this investigation.

\section{Experimental}

\subsection{Catalyst Syntheses}

The four nickel-based catalysts, $\mathrm{Ni} / \mathrm{SiO}_{2}, \mathrm{Ni} / \mathrm{ZrO}{ }_{2}, \mathrm{NiCu} / \mathrm{SiO}_{2}$ and $\mathrm{NiCu} / \mathrm{ZrO}_{2}$, were synthesized by wet impregnation as follows. Both supports (silica and zirconia from Alfa Aesar, Haverhill, MA, USA) were milled to $0.125-0.250 \mathrm{~mm}$ and added to the metal solution in a ratio of 1:10. The metal precursors were $\mathrm{Ni}\left(\mathrm{NO}_{3}\right)_{2} \cdot 6 \mathrm{H}_{2} \mathrm{O}$ (Sigma-Aldrich, St. Louis, MI, USA) and $\mathrm{Cu}\left(\mathrm{NO}_{3}\right)_{2} \cdot 2.5 \mathrm{H}_{2} \mathrm{O}$ (Alfa Aesar, Haverhill, MA, USA). The water was evaporated at $35{ }^{\circ} \mathrm{C}, 45 \mathrm{mbar}, 100 \mathrm{rpm}$ in a rotary evaporator (Hei-VAP Advantage ML/G3) and the formed catalyst was dried for $12 \mathrm{~h}$ at $105^{\circ} \mathrm{C}$. The catalysts were then calcined at $450{ }^{\circ} \mathrm{C}$ for $4 \mathrm{~h}$ after reaching the set point, with a heating ramp of $10{ }^{\circ} \mathrm{C} / \mathrm{min}$ (Thermolyne F6010) and later reduced in a $25 \% \mathrm{H}_{2} / \mathrm{N}_{2}$ flow of $3 \mathrm{~L} / \mathrm{min}$, heating ramp of $5 \mathrm{~K} / \mathrm{min}$, during $4 \mathrm{~h}$. The reduction temperatures were defined by temperature programmed reduction $\left(\mathrm{H}_{2}\right.$-TPR) experiments (see Sections 2.1 and 4.5). Regarding the monometallic Ni catalyst, the metal concentration in the catalyst was defined in $8.6 \mathrm{wt} . \%$ [78] while, for the bimetallic catalysts, the metal concentration was defined in $28 \mathrm{wt} . \%$ of $\mathrm{Ni}$ and $3.5 \mathrm{wt} . \% \mathrm{Cu}$ [23].

\subsection{Beech Wood Fast-Pyrolysis Bio-Oil}

The experiments were carried out with a beech wood fast-pyrolysis bio-oil (BTG Group, Enschede, The Netherlands). Following intentional aging $\left(24 \mathrm{~h}, 80^{\circ} \mathrm{C}\right)$ two phases were observed. The final oil was then composed by $41 \mathrm{wt} . \%$ of heavy phase (HP) and $59 \mathrm{wt} . \%$ of light phase (LP), respectively. Both phases were separated, and previously characterized separately, as presented elsewhere [43]. The main physicochemical properties and elemental analyses are presented (Table 9).

Table 9. Physicochemical properties and elemental analysis of the HP and LP of aged beech wood fast pyrolysis bio-oil [43].

\begin{tabular}{ccc}
\hline \multirow{2}{*}{ Properties } & \multicolumn{2}{c}{ Beechwood Fast-Pyrolysis Bio-Oil } \\
\cline { 2 - 3 } & HP & LP \\
\hline Carbon (wt.\%) (wet basis; dry basis) & $54.3 ; 63.7$ & $34.3 ; 52.4$ \\
Hydrogen (wt.\%) (wet basis; dry basis) & $7.5 ; 6.9$ & $8.3 ; 6.8$ \\
Nitrogen (wt.\%) (wet basis; dry basis) & $<0.2$ & $<0.2$ \\
Oxygen (wt.\%) (wet basis; dry basis) & $38.2 ; 29.2$ & $57.3 ; 39.9$ \\
Sulfur (wt.\%) (wet basis; dry basis) & $0.009 ; 0.011$ & $0.015 ; 0.023$ \\
$\mathbf{H}_{\mathbf{2}}$ O (wt.\%) & 14.5 & 35.3 \\
HHV (MJ/kg) (wet basis; dry basis) & $23.1 ; 27.3$ & $14.1 ; 22.4$ \\
pH value & 3 & 2.7 \\
Density (g/cm ${ }^{3}$ ) & 1.19 & 1.17 \\
\hline
\end{tabular}




\subsection{HDO Reactions}

The HDO (hydrodeoxygenation) experiments were conducted in a $200 \mathrm{~mL}$ volume batch reactor. More details about the reactor are given in the Supplementary Material. The conditions selected for this study were fixed to $325^{\circ} \mathrm{C}$ and 80 bar of $\mathrm{H}_{2}$ based on the current authors' previous investigation [47]. Fifty grams of bio-oil (composed of the mixture of the LP and HP, in the proportion advised in Section 4.2) and $5 \mathrm{wt} . \%$ of catalyst in relation to the amount of the bio-oil were added to the autoclave. The reactor was closed and purged with $\mathrm{N}_{2}$ for $5 \mathrm{~min}$ and pressurized with $\mathrm{H}_{2}$ (Air liquid Alphagaz 2, purity 6.0) at ambient temperature. The stirrer was switched to $1000 \mathrm{rpm}$ and the heating program was started at a rate of $5{ }^{\circ} \mathrm{C} / \mathrm{min}$. The global reaction time, including the heating ramp, was $120 \mathrm{~min}$. When this time was reached, the reaction was quenched first using a flow of compressed air and, later, in a cold water bath with ice, until reaching ambient temperature. Two experiments were performed for each set of conditions and are presented as an average.

Following the reaction, the final pressure was recorded for hydrogen consumption determination and the gas phase was collected for gas chromatography analysis. The mixture of spent catalyst, coke/char, upgraded bio-oil and aqueous phase was collected, centrifuged for $40 \mathrm{~min}$ at $7000 \mathrm{rpm}$ in a Heraeus Biofuge Stratos centrifuge (Thermo Fischer Scientific, Waltham, MA, USA) and then separated for further characterization. The $\mathrm{H}_{2}$ consumption was calculated using the ideal gas law, as the difference of the moles of hydrogen loaded to the reactor and the remaining moles after the hydrotreatment, from the pressure before and after the reaction and the gas composition determined by gas chromatography [40].

\subsection{Products Characterization}

The gas composition was determined by collecting and analyzing the gaseous fraction by gas chromatography. A $100 \mu \mathrm{L}$ sample was injected at $250^{\circ} \mathrm{C}$ (split 28:1) in an Agilent 7890A (two detectors: thermal conductivity and flame ionization detector, TCD and FID respectively) equipped with two columns: Restek 79,096 Hayesep Q and Restek Molsieve 5A. The oven temperature was programmed as follows: the initial temperature was set to $50{ }^{\circ} \mathrm{C}$ maintained for $10 \mathrm{~min}$; increased to $90{ }^{\circ} \mathrm{C}$ at a heating rate of $3{ }^{\circ} \mathrm{C}$ per minute and then increased to $150{ }^{\circ} \mathrm{C}$ at a heating rate of $20^{\circ} \mathrm{C}$ per minute, maintained at this temperature for $16 \mathrm{~min}$ and finally heated to $230{ }^{\circ} \mathrm{C}$ at $50^{\circ} \mathrm{C}$ per minute and kept for $10 \mathrm{~min}$.

The liquid products (aqueous phase and upgraded bio-oil) were characterized using the same methodology, except the higher heating value (HHV), which was not determined for the aqueous phases. The $\mathrm{pH}$ values were measured with a $\mathrm{pH}$-meter from Metrohm. The HHV was determined using a calorimeter IKA C5000 control and the water content using a volumetric Karl-Fischer titrator from Metrohm (Titrando 841, titration reagents Composite 5 and dry Methanol). Carbon, hydrogen, and nitrogen content were measured using a micro-elemental analyzer Elementar Vario el Cube. The content of oxygen was estimated by the difference.

Quantitative ${ }^{1} \mathrm{H}-\mathrm{NMR}$ (proton nuclear magnetic resonance) was employed to characterize the functional groups in the product molecules, based on the number of protons in the corresponding ${ }^{1} \mathrm{H}$-shift range [44]. ${ }^{1} \mathrm{H}$-NMR spectra were recorded at $25{ }^{\circ} \mathrm{C}$ on a Bruker Biospin spectrometer, equipped with a $5.47 \mathrm{~T}$ magnet $\left({ }^{1} \mathrm{H}\right.$ frequency $\left.250 \mathrm{~Hz}\right)$. Sample preparation consisted of $0.1 \mathrm{~g}$ of either upgraded bio-oil or aqueous phase and their dilution in $0.7 \mathrm{~g}$ of deuterated methanol $\left(\mathrm{CD}_{3} \mathrm{OD}\right)$ containing TMSP-d4 [3-(trimethylsilyl)-2,2,3,3-tetradeuteropropionic acid sodium salt] as an internal standard ( $0.1 \mathrm{~g}$ TMSP in $50 \mathrm{~mL} \mathrm{CD} \mathrm{CD}_{3} \mathrm{OD}$ ). Subsequently, the samples were centrifuged (removal of particles not solubilized) and placed in NMR tubes.

The liquid samples also were analyzed qualitatively using a gas chromatography mass spectrometer (GC-MS) HPG1800A, with a Restek stabilwax column. Prior to measurement, the samples were diluted in methanol and filtrated using a $0.25 \mu \mathrm{m}$ filter. A $1 \mu \mathrm{L}$ sample was injected at $250{ }^{\circ} \mathrm{C}$, with a split of 1:20. The oven temperature was programmed as follows: the initial temperature was 
set to $40{ }^{\circ} \mathrm{C}$, maintained for $5 \mathrm{~min}$; increased to $300{ }^{\circ} \mathrm{C}$ with a heating rate of $20^{\circ} \mathrm{C}$ per minute and maintained for $20 \mathrm{~min}$ at this condition.

\subsection{Catalysts Characterization}

The concentration of metal in the catalysts was analyzed by ICP-OES (Inductively Coupled Plasma Emission Spectroscopy Agilent 725 Spectrometer). The sample was dissolved using a mixture of $\mathrm{HNO}_{3}$ ( $2 \mathrm{~mL}), \mathrm{HCl}(6 \mathrm{~mL})$ and $\mathrm{H}_{2} \mathrm{O}_{2}(0.5 \mathrm{~mL})$ and digested in a microwave oven for $45 \mathrm{~min}$ at $240{ }^{\circ} \mathrm{C}$.

To determine the reduction temperature profile of the active metal, an Autochem HP 2950 (Micrometrics, Ottawa, ON, Canada) was used for the temperature programmed reduction by hydrogen $\left(\mathrm{H}_{2}\right.$-TPR). The measurements were performed at a heating rate of $1 \mathrm{~K} / \mathrm{min}$ until $500{ }^{\circ} \mathrm{C}$ and $5 \% \mathrm{H}_{2}$ in Ar at $30 \mathrm{~mL} / \mathrm{min}$. The samples were dried in a $30 \mathrm{~mL} / \mathrm{min}$ flow of $\mathrm{Ar}$ at $300{ }^{\circ} \mathrm{C}$ for $3 \mathrm{~h}$ before the measurement.

The total specific surface area of the catalyst was determined by nitrogen physisorption with a Belsorp Mini II at $77 \mathrm{~K}$ and calculated by applying the BET theory in the fitting rate between 0.05-0.30 p/p0 (12 points). Powder XRD was measured using an X'Pert PRO MPD instrument (PANalytical GmbH, Nuremberg, BY, Germany) equipped with a $\mathrm{Cu}$ anode ( $\mathrm{Cu} \mathrm{K} \alpha 1.54060 \AA$ ). The XRD patterns were recorded in a $2 \theta$ range between $5-120^{\circ}\left(1 \mathrm{~h}\right.$, step size $\left.0.017^{\circ}\right)$. The average crystallite size was estimated using the Scherrer equation (shape factor $\mathrm{K}=0.9$ ) after correcting the instrumental line broadening.

Leaching of the catalyst was monitored by analyzing the aqueous phase by ICP-OES. Sample preparation involved the filtration with a $0.2 \mu \mathrm{m}$ polytetrafluoroetylen (PTFE) filter membrane of the produced aqueous phase after each reaction.

To identify the elements present on the particles of fresh and spent catalysts, SEM/EDX (Scanning Electron Microscopy/Energy Dispersive X-ray spectroscopy) was applied. The equipment for this technique was a GeminiSEM 500, Zeiss, software SmartSEM Version 6.01, with a thermal Schottky field-emitter cathode. An energy dispersive X-ray spectrometer X-Max ${ }^{\mathrm{N}}$ from Oxford with a silicon drift detector $\left(80 \mathrm{~mm}^{2}\right.$ and resolution of $\left.127 \mathrm{eV}\right)$ was employed for the quantitative analysis of micro areas and the distribution of the elements, in addition to the software Aztec 3.3. The C, H, N and S of the spent catalysts were measured by a micro-elemental analyzer Elementar Vario el Cube. The solid over the spent catalysts (coke) was calculated by the carbon concentration over the spent catalyst (determined by elemental analysis), considering oxygen concentration negligible [46]. More detail is given in the Supplementary Materials (Equation (S1)).

\subsection{Catalyst Regeneration}

Based on the experimental results, such as oxygen content, water concentration, solid and gas production as well as upgraded bio-oil yield, one of the catalysts was selected for further application in cycles of HDO and regeneration. The cycles each consisted of an HDO reaction, calcination of the spent catalyst (as described in Section 4.1), followed by a reduction and a subsequent HDO reaction. Altogether, the catalyst was used four times. To evaluate the behavior of the catalyst over the consecutive uses, the spent catalyst was analyzed through SEM-EDX and XRD between the regenerations: EDX was performed for the spent and reduced catalysts, whereas XRD was performed for the spent, calcined, and reduced catalysts. Furthermore, the upgraded products also were characterized along the cycles, as described in Section 4.4.

\section{Conclusions}

Four nickel-based catalysts on different supports were synthesized and evaluated for the HDO of a multi-phase beech wood fast-pyrolysis bio-oil. The bimetallic catalysts showed lower reduction temperature, attributed to the addition of copper, and higher metal loading. Furthermore, $\mathrm{NiCu}$ catalysts presented higher consumption of hydrogen and different selectivity toward the conversion of compounds such as furfural, compared to monometallic catalysts. Upgraded bio-oils 
with reduced concentration of oxygen, lower water concentration and higher carbon content were obtained after the HDO reactions. $\mathrm{Ni} / \mathrm{SiO}_{2}$, in particular, showed the highest HDO activity, reducing more than $50 \%$ of the oxygen content and more than $80 \%$ of the water content, thus selected for application in cycles of regeneration-reaction. During the consecutive reactions, the activity of the catalyst decreased, attributed mainly to sintering and poisoning by sulfur, as coke was removed easily during the regeneration steps. Lower hydrogen consumption and higher carbon dioxide production were observed in comparison to the reactions when applying the fresh catalyst. Correlating the results obtained by ${ }^{1} \mathrm{H}-\mathrm{NMR}$ and GC-MS, it was possible to observe that compounds known as sugar derivatives were being reduced along the consecutive reactions while the concentration of protons in the region attributed to water, carbohydrates and O-H exchange increased. The partial loss of activity seemed to lower the conversion of sugars.

Accompanying that, the catalysts evaluated seemed to be suitable for HDO of hardwood fast-pyrolysis bio-oil, especially $\mathrm{Ni} / \mathrm{SiO}_{2}$. Further investigation will be addressed, considering a detailed investigation of model compound conversions and the effect of sulfur and calcium over HDO of single compounds. The influence of sintering over the activity and selectivity will also be investigated. Due to the limitation of the batch reactor for deactivation mechanism studies, the application of a trickle bed reactor in future studies is intended.

Supplementary Materials: The following are available online at http:/ /www.mdpi.com/2073-4344/8/10/449/ s1.

Author Contributions: C.C.S. design the experiments, performed part of the experiments, analyzed the data and wrote the paper; M.B.G.R. performed most of the experiments and analyzed the data; M.Z. contributed with the microscopy experiments; J.-D.G., K.R. and N.D. contributed with the discussion, reviewed and supervised the work.

Funding: This research received no external funding.

Acknowledgments: The authors are grateful to the Bioeconomy Graduate Program-BBWForwerts, Brazilian National Council for Science and Technology (CNPQ) and BeMundus for the financial support. The authors are also grateful to Herman Köhler, Pia Griesheimer, Petra Janke, Jessica Heinrich, and Simon Wodarz for the support with analytical techniques, Oliver Schade for the support with the catalyst reduction oven and to the assistant bachelor student (Hiwi student) Mouhannad Moulla, for the activities developed during his internship which supported the development of this work.

Conflicts of Interest: The authors declare no conflict of interest.

\section{References}

1. Kan, T.; Strezov, V.; Evans, T.J. Lignocellulosic biomass pyrolysis: A review of product properties and effects of pyrolysis parameters. Renew. Sustain. Energy Rev. 2016, 57, 1126-1140. [CrossRef]

2. García-Olivares, A.; Solé, J.; Osychenko, O. Transportation in a $100 \%$ renewable energy system. Energy Convers. Manag. 2018, 158, 266-285. [CrossRef]

3. Balsalobre-Lorente, D.; Shahbaz, M.; Roubaud, D.; Farhani, S. How economic growth, renewable electricity and natural resources contribute to $\mathrm{CO}_{2}$ emissions? Energy Policy 2018, 113, 356-367. [CrossRef]

4. Guedes, R.E.; Luna, A.S.; Torres, A.R. Operating parameters for bio-oil production in biomass pyrolysis: A review. J. Anal. Appl. Pyrolysis 2018, 129, 134-149. [CrossRef]

5. Bridgwater, A.V. Renewable fuels and chemicals by thermal processing of biomass. Chem. Eng. J. 2003, 91, 87-102. [CrossRef]

6. El Bassam, N. Handbook of Bioenergy Crops. A Complete Reference to Species, Development and Applications; Routledge: Abingdon-on-Thames, UK, 2010; Volume 18, ISBN 978-1-84407-854-7.

7. Sharma, A.; Pareek, V.; Zhang, D. Biomass pyrolysis-A review of modelling, process parameters and catalytic studies. Renew. Sustain. Energy Rev. 2015, 50, 1081-1096. [CrossRef]

8. Si, Z.; Zhang, X.; Wang, C.; Ma, L.; Dong, R. An Overview on Catalytic Hydrodeoxygenation of Pyrolysis Oil and Its Model Compounds. Catalysts 2017, 7, 169. [CrossRef]

9. Czernik, S.; Johnson, D.K.; Black, S. Stability of wood fast pyrolysis oil. Biomass Bioenergy 1994, 7, 187-192. [CrossRef] 
10. Olbrich, W.; Boscagli, C.; Raffelt, K.; Zang, H.; Dahmen, N.; Sauer, J. Catalytic hydrodeoxygenation of pyrolysis oil over nickel-based catalysts under $\mathrm{H}_{2} / \mathrm{CO}_{2}$ atmosphere. Sustain. Chem. Process. 2016, 4, 9. [CrossRef]

11. Li, X.; Gunawan, R.; Wang, Y.; Chaiwat, W.; Hu, X.; Gholizadeh, M.; Mourant, D.; Bromly, J.; Li, C.-Z. Upgrading of bio-oil into advanced biofuels and chemicals. Part III. Changes in aromatic structure and coke forming propensity during the catalytic hydrotreatment of a fast pyrolysis bio-oil with $\mathrm{Pd} / \mathrm{C}$ catalyst. Fuel 2014, 116, 642-649. [CrossRef]

12. Balat, M. An overview of the properties and applications of biomass pyrolysis oils. Energy Sources Part A Recover. Util. Environ. Eff. 2011, 33, 674-689. [CrossRef]

13. Bridgwater, A.V. Review of fast pyrolysis of biomass and product upgrading. Biomass Bioenergy 2012, 38, 68-94. [CrossRef]

14. Gollakota, A.R.K.; Reddy, M.; Subramanyam, M.D.; Kishore, N. A review on the upgradation techniques of pyrolysis oil. Renew. Sustain. Energy Rev. 2016, 58, 1543-1568. [CrossRef]

15. Mortensen, P.M.; Grunwaldt, J.-D.; Jensen, P.A.; Knudsen, K.G.; Jensen, A.D. A review of catalytic upgrading of bio-oil to engine fuels. Appl. Catal. A Gen. 2011, 407, 1-19. [CrossRef]

16. Furimsky, E. Catalytic hydrodeoxygenation. Appl. Catal. A Gen. 2000, 199, 147-190. [CrossRef]

17. Song, H.; Gong, J.; Song, H.; Li, F. Applied Catalysis A: General A novel surface modification approach for synthesizing supported nickel phosphide catalysts with high activity for hydrodeoxygenation of benzofuran. Appl. Catal. A Gen. 2015, 505, 267-275. [CrossRef]

18. Elliott, D.C. Biofuel from fast pyrolysis and catalytic hydrodeoxygenation. Curr. Opin. Chem. Eng. 2015, 9, 59-65. [CrossRef]

19. Ewald, S.; Standl, S.; Hinrichsen, O. Characterization of nickel catalysts with transient methods. Appl. Catal. A Gen. 2018, 549, 93-101. [CrossRef]

20. Jin, S.; Xiao, Z.; Li, C.; Chen, X.; Wang, L.; Xing, J.; Li, W.; Liang, C. Catalytic hydrodeoxygenation of anisole as lignin model compound over supported nickel catalysts. Catal. Today 2014, 234, 125-132. [CrossRef]

21. Boscagli, C.; Raffelt, K.; Zevaco, T.A.; Olbrich, W.; Otto, T.N.; Sauer, J.; Grunwaldt, J.-D. Mild hydrotreatment of the light fraction of fast-pyrolysis oil produced from straw over nickel-based catalysts. Biomass Bioenergy 2015, 83, 525-538. [CrossRef]

22. Dongil, A.B.; Ghampson, I.T.; García, R.; Fierro, J.L.G.; Escalona, N. Hydrodeoxygenation of guaiacol over $\mathrm{Ni}$ /carbon catalysts: Effect of the support and Ni loading. RSC Adv. 2016, 6, 2611-2623. [CrossRef]

23. Ardiyani, A.R.; Khromova, S.A.; Venderbosch, R.H.; Yakovlev, V.A.; Heeres, H.J. Catalytic hydrotreatment of fast-pyrolysis oil using non-sulfided bimetallic $\mathrm{Ni}-\mathrm{Cu}$ catalysts on a $\delta-\mathrm{Al}_{2} \mathrm{O}_{3}$ support. Appl. Catal. B Environ. 2012, 117-118, 105-117. [CrossRef]

24. Dongil, A.B.; Bachiller-Baeza, B.; Rodriguez-Ramos, I.; Fierro, J.L.G.; Escalona, N. Effect of Cu loading on $\mathrm{Ni}$ /carbon nanotubes catalyst for hydrodeoxygenation of guaiacol. RSC Adv. 2016, 3, 26658-26667. [CrossRef]

25. Mortensen, P.M.; Grunwaldt, J.-D.; Jensen, P.A.; Jensen, A.D. Screening of catalysts for hydrodeoxygenation of phenol as a model compound for bio-oil. ACS Catal. 2013, 3, 1774-1785. [CrossRef]

26. Boscagli, C.; Yang, C.; Welle, A.; Wang, W.; Behrens, S.; Raffelt, K.; Grunwaldt, J.-D. Effect of pyrolysis oil components on the activity and selectivity of nickel-based catalysts during hydrotreatment. Appl. Catal. A Gen. 2017, 544, 161-172. [CrossRef]

27. Saidi, M.; Samimi, F.; Karimipourfard, D.; Nimmanwudipong, T.; Gates, B.C.; Rahimpour, M.R. Upgrading of lignin-derived bio-oils by catalytic hydrodeoxygenation. Energy Environ. Sci. 2014, 7, 103-129. [CrossRef]

28. He, Z.; Wang, X. Hydrodeoxygenation of model compounds and catalytic systems for pyrolysis bio-oils upgrading. Catal. Sustain. Energy 2012, 1, 28-52. [CrossRef]

29. Elliott, D.C. Historical developments in hydroprocessing bio-oils. Energy Fuels 2007, 21, $1792-1815$. [CrossRef]

30. Bykova, M.V.; Ermakov, D.Y.; Kaichev, V.V.; Bulavchenko, O.A.; Saraev, A.A.; Lebedev, M.Y.; Yakovlev, V.A. Applied Catalysis B: Environmental Ni-based sol-gel catalysts as promising systems for crude bio-oil upgrading: Guaiacol hydrodeoxygenation study. Appl. Catal. B Environ. 2012, 113-114, 296-307. [CrossRef]

31. Roldugina, E.A.; Naranov, E.R.; Maximov, A.L.; Karakhanov, E.A. Hydrodeoxygenation of guaiacol as a model compound of bio-oil in methanol over mesoporous noble metal catalysts. Appl. Catal. A Gen. 2018. [CrossRef] 
32. Esmaeili, J.; Rahimpour, F. Regeneration of spent nickel catalyst from hydrogenation process of edible oils: Heat treatment with hydrogen injection. Int. J. Hydrogen Energy 2017, 42, 24197-24204. [CrossRef]

33. Ng, A.; Lup, K.; Abnisa, F.; Mohd, W.; Wan, A. A review on reactivity and stability of heterogeneous metal catalysts for deoxygenation of bio-oil model compounds. J. Ind. Eng. Chem. 2017, 56, 1-34. [CrossRef]

34. Koike, N.; Hosokai, S.; Takagaki, A.; Nishimura, S.; Kikuchi, R.; Ebitani, K.; Suzuki, Y.; Oyama, S.T. Upgrading of pyrolysis bio-oil using nickel phosphide catalysts. J. Catal. 2016, 333, 115-126. [CrossRef]

35. Yin, W.; Hendrikus, R.; Alekseeva, M.V.; Bernardes, M.; Heeres, H.; Khromova, A.; Yakovlev, V.A.; Cannilla, C.; Bonura, G.; Frusteri, F.; et al. Hydrotreatment of the carbohydrate-rich fraction of pyrolysis liquids using bimetallic Ni based catalyst: Catalyst activity and product property relations. Fuel Process. Technol. 2018, 169, 258-268. [CrossRef]

36. Rodríguez, J.C.; Marchi, A.J.; Borgna, A.; Romeo, E.; Monzón, A. Gas Phase Selective Hydrogenation of Acetylene. Importance of the Formation of Ni-Co and Ni-Cu Bimetallic Clusters on the Selectivity and Coke Deposition. Stud. Surf. Sci. Catal. 2001, 139, 37-44. [CrossRef]

37. De Rogatis, L.; Montini, T.; Lorenzut, B.; Fornasiero, P. NixCuy/ $\mathrm{Al}_{2} \mathrm{O}_{3}$ based catalysts for hydrogen production. Energy Environ. Sci. 2008, 1, 501-509. [CrossRef]

38. Li, X.; Cheng, H.; Liang, G.; He, L.; Lin, W.; Yu, Y.; Zhao, F. Effect of Phosphine Doping and the Surface Metal State of $\mathrm{Ni}$ on the Catalytic Performance of $\mathrm{Ni} / \mathrm{Al}_{2} \mathrm{O}_{3}$ Catalyst. Catalysts 2015, 5, 759-773. [CrossRef]

39. Jahromi, H.; Agblevor, F.A. Hydrodeoxygenation of pinyon-juniper catalytic pyrolysis oil using red mud-supported nickel catalysts. Appl. Catal. B Environ. 2018, 236, 1-12. [CrossRef]

40. Ardiyanti, A.R.; Khromova, S.A.; Venderbosch, R.H.; Yakovlev, V.A.; Melián-Cabrera, I.V.; Heeres, H.J. Catalytic hydrotreatment of fast pyrolysis oil using bimetallic $\mathrm{Ni}-\mathrm{Cu}$ catalysts on various supports. Appl. Catal. A Gen. 2012, 449, 121-130. [CrossRef]

41. Wang, Z.; Zeng, Y.; Lin, W.; Song, W. In-situ hydrodeoxygenation of phenol by supported Ni catalyst-Explanation for catalyst performance. Int. J. Hydrogen Energy 2017, 42, 21040-21047. [CrossRef]

42. Zhang, X.; Wang, T.; Ma, L.; Zhang, Q.; Yu, Y.; Liu, Q. Characterization and catalytic properties of Ni and $\mathrm{NiCu}$ catalysts supported on $\mathrm{ZrO}_{2}-\mathrm{SiO}_{2}$ for guaiacol hydrodeoxygenation. Catal. Commun. 2013, 33, 15-19. [CrossRef]

43. Carriel Schmitt, C.; Boscagli, C.; Rapp, M.; Raffelt, K.; Dahmen, N. Characterization of light and heavy phase of pyrolysis-oil from distinct biomass for further upgrading reactions. In Proceedings of the 25th European Biomass Conference and Exhibition, Stockholm, Sweden, 12-15 June 2017. [CrossRef]

44. Mullen, C.A.; Strahan, G.D.; Boateng, A.A. Characterization of various fast-pyrolysis bio-oils by NMR spectroscopy. Energy Fuels 2009, 23, 2707-2718. [CrossRef]

45. Yin, W.; Kloekhorst, A.; Venderbosch, R.H.; Bykova, M.V.; Khromova, S.A.; Yakovlev, V.A.; Heeres, H.J. Catalytic hydrotreatment of fast pyrolysis liquids in batch and continuous set-ups using a bimetallic Ni-Cu catalyst with a high metal content. Catal. Sci. Technol. 2016, 6, 5899-5915. [CrossRef]

46. Boscagli, C.; Raffelt, K.; Grunwaldt, J.-D. Reactivity of platform molecules in pyrolysis oil and in water during hydrotreatment over nickel and ruthenium catalysts. Biomass Bioenergy 2017, 106, 63-73. [CrossRef]

47. Schmitt, C.C.; Raffelt, K.; Zimina, A.; Krause, B.; Otto, T.; Rapp, M.; Grunwaldt, J.-D.; Dahmen, N. Hydrotreatment of Fast Pyrolysis Bio-oil Fractions Over Nickel-Based Catalyst. Top. Catal. 2018, 61, 1769-1782. [CrossRef]

48. Oh, S.; Choi, H.S.; Choi, I.-G.; Choi, J.W. Evaluation of hydrodeoxygenation reactivity of pyrolysis bio-oil with various Ni-based catalysts for improvement of fuel properties. RSC Adv. 2017, 7, 15116-15126. [CrossRef]

49. Nakagawa, Y.; Tamura, M.; Tomishige, K. Catalytic Conversions of Furfural to Pentanediols. Catal. Surv. Asia 2015, 19, 249-256. [CrossRef]

50. Resasco, D.E.; Sitthisa, S.; Faria, J.; Prasomsri, T.; Ruiz, M.P. Furfurals as Chemical Platform for Biofuels Production; Kubička, D., Kubičková, I., Eds.; Research S.: Kerala, India, 2011; Volume 661, ISBN 9788130804620.

51. Mariscal, R.; Maireles-Torres, P.; Ojeda, M.; Sádaba, I.; López Granados, M. Furfural: A renewable and versatile platform molecule for the synthesis of chemicals and fuels. Energy Environ. Sci. 2016, 9, 1144-1189. [CrossRef]

52. Feng, J.; Yang, Z.; Hse, C.Y.; Su, Q.; Wang, K.; Jiang, J.; Xu, J. In situ catalytic hydrogenation of model compounds and biomass-derived phenolic compounds for bio-oil upgrading. Renew. Energy 2017, 105, 140-148. [CrossRef] 
53. Agblevor, F.A.; Jahromi, H. Aqueous phase synthesis of hydrocarbons from furfural reactions with low molecular weight biomass oxygenates. Energy Fuels 2018, 32, 8552-8562. [CrossRef]

54. Vispute, T. Pyrolysis Oils: Characterization, Stability Analysis, and Catalytic Upgrading to Fuels and Chemicals. Ph.D. Thesis, University of Massachussets Amherst, Amherst, MA, USA, 2011.

55. Deutsch, K.L. Copper Catalysts in the C-O Hydrogenolysis of Biorenewable Compounds. Ph.D. Thesis, Iowa State University, Ames, IA, USA, 2012.

56. Khromova, S.A.; Smirnov, A.A.; Bulavchenko, O.A.; Saraev, A.A.; Kaichev, V.V.; Reshetnikov, S.I.; Yakovlev, V.A. Anisole hydrodeoxygenation over Ni-Cu bimetallic catalysts: The effect of Ni/Cu ratio on selectivity. Appl. Catal. A Gen. 2014, 470, 261-270. [CrossRef]

57. French, R.J.; Stunkel, J.; Black, S.; Myers, M.; Yung, M.M.; Iisa, K. Evaluate impact of catalyst type on oil yield and hydrogen consumption from mild hydrotreating. Energy Fuels 2014, 28, 3086-3095. [CrossRef]

58. Huynh, T.M. Development of Novel Bimetallic Nickel-Cobalt Catalysts for Hydrodeoxygenation of Bio-Oil Producing a Co-Feed for a Standard Refinery Unit. Ph.D. Thesis, University of Rostock, Rostock, Germany, 2015.

59. Ardiyanti, A.R.; Gutierrez, A.; Honkela, M.L.; Krause, A.O.I.I.; Heeres, H.J. Hydrotreatment of wood-based pyrolysis oil using zirconia-supported mono- and bimetallic (Pt, Pd, Rh) catalysts. Appl. Catal. A Gen. 2011, 407, 56-66. [CrossRef]

60. Van Haasterecht, T.; Ludding, C.C.I.; De Jong, K.P.; Bitter, J.H. Toward stable nickel catalysts for aqueous phase reforming of biomass-derived feedstock under reducing and alkaline conditions. J. Catal. 2014, 319, 27-35. [CrossRef]

61. Argyle, M.D.; Bartholomew, C.H. Heterogeneous Catalyst Deactivation and Regeneration: A Review. Catalysts 2015, 5, 145-269. [CrossRef]

62. Oh, S.; Hwang, H.; Seok, H.; Weon, J. The effects of noble metal catalysts on the bio-oil quality during the hydrodeoxygenative upgrading process. Fuel 2015, 153, 535-543. [CrossRef]

63. Li, X.; Luo, X.; Jin, Y.; Li, J.; Zhang, H.; Zhang, A.; Xie, J. Heterogeneous sulfur-free hydrodeoxygenation catalysts for selectively upgrading the renewable bio-oils to second generation biofuels. Renew. Sustain. Energy Rev. 2018, 82, 3762-3797. [CrossRef]

64. Chen, S.; Miao, C.; Luo, Y.; Zhou, G.; Xiong, K.; Jiao, Z. Study of catalytic hydrodeoxygenation performance of Ni catalysts: Effects of prepared method. Renew. Energy 2018, 115, 1109-1117. [CrossRef]

65. González-Cobos, J.; de Lucas-Consuegra, A. A Review of Surface Analysis Techniques for the Investigation of the Phenomenon of Electrochemical Promotion of Catalysis with Alkaline Ionic Conductors. Catalysts 2016, 6, 15. [CrossRef]

66. Mortensen, P.M.; Gardini, D.; de Carvalho, H.W.P.; Damsgaard, C.D.; Grunwaldt, J.-D.; Jensen, P.A.; Wagner, J.B.; Jensen, A.D. Catalysis Science \& Technology of sulfur, potassium, and chlorine in the feed. Catal. Sci. Technol. 2014, 4, 3672-3686. [CrossRef]

67. Hou, L.; Bu, Q.; Li, S.; Wang, D.; Xie, T. $\mathrm{Ni}_{3} \mathrm{~S}_{2}$-Decorated $\mathrm{TiO}_{2}$ nanotube arrays as effective photoanodes for photoelectrochemical water splitting. RSC Adv. 2016, 6, 99081-99087. [CrossRef]

68. Xiong, X.; Zhao, B.; Ding, D.; Chen, D.; Yang, C.; Lei, Y.; Liu, M. One-step synthesis of architectural Ni $\mathrm{N}_{2}$ nanosheet-on-nanorods array for use as high-performance electrodes for supercapacitors. NPG Asia Mater. 2016, 8, e300. [CrossRef]

69. Alonso, D.M.; Wettstein, S.G.; Dumesic, J.A. Bimetallic catalysts for upgrading of biomass to fuels and chemicals. Chem. Soc. Rev. 2012, 41, 8075-8098. [CrossRef] [PubMed]

70. Sanna, A.; Vispute, T.P.; Huber, G.W. Hydrodeoxygenation of the aqueous fraction of bio-oil with Ru/C and Pt/C catalysts. Appl. Catal. B Environ. 2015, 165, 446-456. [CrossRef]

71. Gunawan, R.; Li, X.; Lievens, C.; Gholizadeh, M.; Chaiwat, W.; Hu, X.; Mourant, D.; Bromly, J.; Li, C.Z. Upgrading of bio-oil into advanced biofuels and chemicals. Part I. Transformation of GC-detectable light species during the hydrotreatment of bio-oil using Pd/C catalyst. Fuel 2013, 111, 709-717. [CrossRef]

72. Sitthisa, S.; An, W.; Resasco, D.E. Selective conversion of furfural to methylfuran over silica-supported NiFe bimetallic catalysts. J. Catal. 2011, 284, 90-101. [CrossRef]

73. Jahromi, H.; Agblevor, F.A. Hydrotreating of guaiacol: A comparative study of Red mud-supported nickel and commercial Ni/SiO $2-\mathrm{Al}_{2} \mathrm{O}_{3}$ catalysts. Appl. Catal. A Gen. 2018, 558, 109-121. [CrossRef]

74. Narayanasamy, L.; Murugesan, T. Degradation of Alizarin Yellow R using UV/ $\mathrm{H}_{2} \mathrm{O}_{2}$ Advanced Oxidation Process. Environ. Sci. Technol. 2014, 33, 482-489. [CrossRef] 
75. Srifa, A.; Faungnawakij, K.; Itthibenchapong, V.; Viriya-Empikul, N.; Charinpanitkul, T.; Assabumrungrat, S. Production of bio-hydrogenated diesel by catalytic hydrotreating of palm oil over $\mathrm{NiMoS}_{2} / \gamma-\mathrm{Al}_{2} \mathrm{O}_{3}$ catalyst. Bioresour. Technol. 2014, 158, 81-90. [CrossRef] [PubMed]

76. Elliott, D.C.; Hart, T.R.; Neuenschwander, G.G.; Rotness, L.J.; Olarte, M.V.; Zacher, A.H.; Solantausta, Y. Catalytic hydroprocessing of fast pyrolysis bio-oil from pine sawdust. Energy Fuels 2012, 26, 3891-3896. [CrossRef]

77. Venderbosch, R.H.; Ardiyanti, A.R.; Wildschut, J.; Oasmaa, A.; Heeres, H.J. Stabilization of biomass-derived pyrolysis oils. J. Chem. Technol. Biotechnol. 2010, 85, 674-686. [CrossRef]

78. Zhao, H.Y.; Li, D.; Bui, P.; Oyama, S.T. Hydrodeoxygenation of guaiacol as model compound for pyrolysis oil on transition metal phosphide hydroprocessing catalysts. Appl. Catal. A Gen. 2011, 391, 305-310. [CrossRef]

2018 by the authors. Licensee MDPI, Basel, Switzerland. This article is an open access article distributed under the terms and conditions of the Creative Commons Attribution (CC BY) license (http:// creativecommons.org/licenses/by/4.0/). 